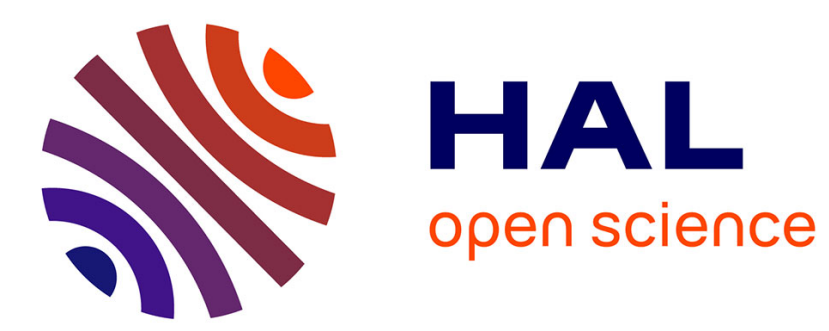

\title{
Metabolic Labeling of Bacterial Glycans
}

Dominique Guianvarc'h, Yann Bourdreux, Christophe Biot, Boris Vauzeilles

\section{To cite this version:}

Dominique Guianvarc'h, Yann Bourdreux, Christophe Biot, Boris Vauzeilles. Metabolic Labeling of Bacterial Glycans. Comprehensive Glycoscience, Elsevier, pp.303-328, 2021, 10.1016/b978-0-12819475-1.00098-5 . hal-03400516

\section{HAL Id: hal-03400516 https://hal.univ-lille.fr/hal-03400516}

Submitted on 25 Oct 2021

HAL is a multi-disciplinary open access archive for the deposit and dissemination of scientific research documents, whether they are published or not. The documents may come from teaching and research institutions in France or abroad, or from public or private research centers.
L'archive ouverte pluridisciplinaire HAL, est destinée au dépôt et à la diffusion de documents scientifiques de niveau recherche, publiés ou non, émanant des établissements d'enseignement et de recherche français ou étrangers, des laboratoires publics ou privés. 


\section{Metabolic Labeling of Bacterial Glycans}

Dominique Guianvarc'h ${ }^{\mathrm{a}}$, Yann Bourdreux ${ }^{\mathrm{a}}$, Christophe Biot $^{\mathrm{b}}$, and Boris Vauzeilles ${ }^{\mathrm{c}},{ }^{\mathrm{a}}$ Institut de Chimie Moléculaire et des Matériaux d'Orsay, Université Paris-Saclay, CNRS, Orsay, France; ${ }^{b}$ UGSF - Unité de Glycobiologie Structurale et Fonctionnelle, University Lille, CNRS, Lille, France and ${ }^{\mathrm{c}}$ Institut de Chimie des Substances Naturelles, Université Paris-Saclay, CNRS, Gif-sur-Yvette, France

(C) 2020 .

Email addresses: dominique.guianvarch@universite-paris-saclay.fr (D. Guianvarc'h); yann.bourdreux@universite-paris-saclay.fr (Y. Bourdreux); christophe.biot@univ-lille.fr (C. Biot); boris.vauzeilles@cnrs.fr (B. Vauzeilles)

\section{Abbreviations}

Ac Acetyl

ADP Adenosine Diphosphate

AG Arabinogalactan

mAGP Mycoloyl-Arabinogalactan-Peptidoglycan complex

Alt L-Altrose

Alk Alkyne

Araf D-Arabinofuranosyl

Asn Asparagine

ATP Adenosine Triphosphate

Az Azide

Bac D-Bacillosamine

BARAC Biarylazacyclooctynone

BCG Bacille Calmette Guerin

Bn Benzyl

Bz Benzoyl

Cbz Benzyloxycarbonyl

CDG-Tre Cephalosporinase-dependent green trehalose

CMP Cytidine Monophosphate

CTP Cytidine Triphosphate

C55-P Undecaprenyl phosphate

CuAAC Copper-catalyzed Azide-Alkyne Cycloaddition

DABCYL 4-(Dimethylaminoazo)benzene-4-carboxylic acid

DATDG 2,4-Diacetamido-2,4,6-trideoxy-D-galactose

DATDH 2,4-Diacetamido-2,4,6-trideoxy-D-hexose

DMN 4- $N, N$-Dimethylamino-1,8-naphthalimide

FITC Fluorescein isothiocyanate

FITre FITC-modified trehaloses

FRAP Fluorescence recovery after photobleaching

Fuc Fucose

Galf D-Galactofuranosyl

GDP Guanosine Diphosphate

GFP Green Fluorescent Protein

Glc D-Glucose

GlcNAc $N$-Acetyl-glucosamine

Glc-1P D-Glucose-1-phosphate

Glc-6P D-Glucose-6-phosphate

GlcN-1P D-Glucosamine-1-phosphate

GIcN-6P D-Glucosamine-6-phosphate

GTP Guanosine Triphosphate
Hep L-Glycero-D-manno-heptose

IEDDA Inverse electron demand Diels-Alder reaction

Kdo 3-Deoxy-D-manno-octulosonic acid

LAM Lipoarabinomannan

Leg Legionaminic acid

Lev Levulinoyl

LM Lipomannan

LPS Lipopolysaccharide

MA Mycolic acid

Me Methyl

MM Mycomembrane

Mtb Mycobacterium tuberculosis

Msmeg Mycobacterium smegmatis

MurNAc $N$-Acetyl-muramic acid

Myt Mycoloyl transferase

PG Peptidoglycan

Ph Phenyl

PIM Phosphatidylinositol mannosides

Pks Polyketide synthase

PMB $p$-Methoxybenzyl

PMP $p$-Methoxyphenyl

Pi Phosphate

PPi Pyrophosphate

Pse Pseudaminic acid

QTF Quencher-Trehalose-Fluorophore

ROS Reactive Oxygen Species

Ser Serine

SPAAC Strain-promoted Azide-Alkyne Cycloaddition

TCO trans-Cyclooctene

TDM Trehalose dimycolate

Tf Trifluoromethanesulfonyl

Thr Threonine

TIPS Triisopropylsilyl

TMM Trehalose monomycolate

TMR Tetramethylrhodamine

TMS Trimethylsilyl

Tre $\alpha, \alpha$-D-Trehalose

UDP Uridine Diphosphate

UDP-GIcNAc Uridine Diphosphate $N$-acetyl-glucosamine UDP-MurNAc Uridine Diphosphate $N$-acetyl-muramic acid

UDP-MurNAc-PP Uridine Diphosphate $N$-acetyl-muramic acid pentapeptide

\section{Introduction}

Over the past 20 years, considerable advances at the interface between chemistry and biology have allowed the development of new chemical tools to study cell processes in the least invasive way possible. Among the different classes of biomolecules, proteins were the first to benefit from the availability of fluorescent probes allowing them to be selectively labeled in order to track them specifically within a living cell or an organism. The Green Fluorescent Protein (GFP) and its many variants effectively allow the precise localization of 
affecting folding and/or localization. ${ }^{3}$ Unfortunately, for other types of non-genetically encoded biomolecules (such as glycans or lipids), imaging techniques based on GFP are not suitable. As a result, it was therefore necessary to develop other visualization technologies for these compounds.

Bioconjugation was the first method used to visualize these classes of biomolecules. This technique initially consisted in the establishment in vitro of a stable covalent bond between the biomolecule of interest and a detectable group (for example, a molecular probe such as a fluorophore or biotin). After metabolic incorporation within target biomolecules (metabolic labeling) by the endogenous enzymatic machinery of the cell, the bioconjugated molecule can then be directly detected via the bioimaging probe (Fig. 1A). Although several interesting applications of these expeditious techniques have been developed, some of which will be presented below, this strategy has some drawbacks: the size and the hydrophobic nature of the pre-labeled probes can limit their ability to mimic the physicochemical properties of the natural precursor. The probes may also not easily enter into the cell, not be recognized or recognized in a different way by biosynthetic pathway enzymes or by transporters, resulting in an incorporation or a localization that do not accurately reflect the reality of the biological processes. Finally, probes already conjugated to a fluorophore have limited versatility, fundamentally limiting their applicability, since a new conjugate has to be synthesized and evaluated for each new application.

\subsection{The bioorthogonal chemical reporter strategy}

To overcome these limitations, an innovative methodology - "the bioorthogonal chemical reporter strategy" - has been developed about 20 years ago enabling scientists to visualize biomolecules in their natural biological environments. Consisting of two distinct steps, this methodology involves the incorporation into the cell of a chemical analog of the molecule of interest tagged with a small functional group such as an azide, alkyne, alkene or ketone. This group/function is then linked to a detection probe in a second step using a bioorthogonal reaction, thereby making it possible to detect the target molecule in its native environment (Fig. 1B). The mutually selective chemical reactivity of the two functional groups ensures that only the metabolized compounds, once incorporated in the biomolecules of interest, are labeled.

Although the "bioorthogonal" term has been first coined in 2003 by Bertozzi, several methods previously implemented can be considered to be the historical precursors of this concept including the tetracysteine-biarsenic system ${ }^{4}$ or the hydrazide-carbonyl ligations. ${ }^{5-8}$

Used for the first time by the team of Prof. C. Bertozzi in $1997^{7}$ and then officially described in $2003,{ }^{9}$ the bioorthogonal chemical reporter strategy exploits the metabolic machinery of a cell or an organism, studied by way of an unnatural analog of a specific component of the parent biomolecule of interest. This analog should be functionalized with a simple chemical label (named the chemical reporter group) taking into account the fact that the structural modification should not modify (or as little as possible) the physicochemical properties of the molecule of interest. The chemical reporter strategy has benefited from important developments in the field of bioorthogonal reactions.
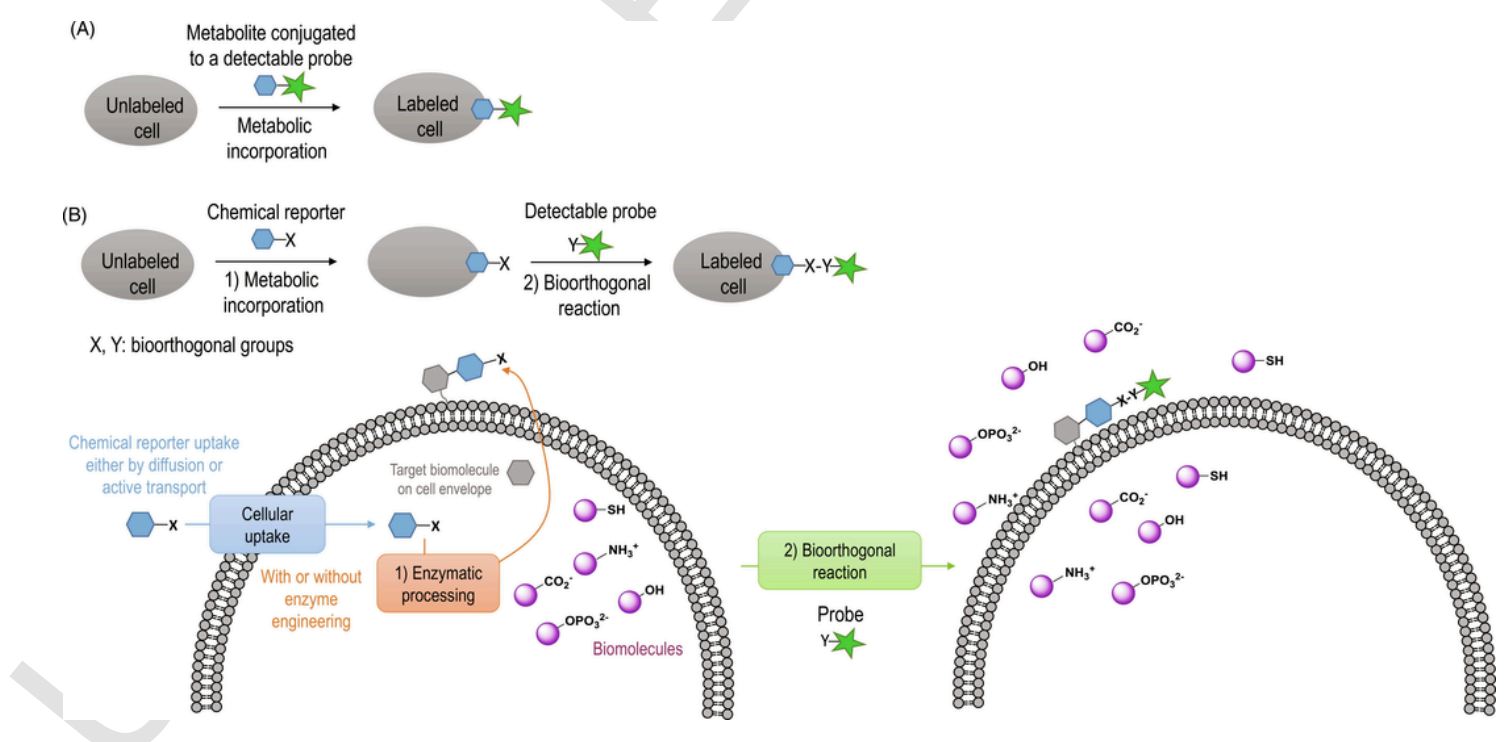

Fig. 1 Schematic representation of cell-selective metabolic labeling of biomolecules in bacteria. (A) One-step metabolic labeling strategy with a detectable probe-labeled metabolite precursor. (B) Two-step metabolic labeling strategy with a metabolite precursor (e.g., a carbohydrate, blue hexagon) functionalized with a small bioorthogonal chemical group (X). In a first step, after uptake of the exogenously added precursor in bacteria, it is processed by the endogenous metabolic machinery and incorporated into the targeted biomolecule. In a second step, the functional group is reacted with a detectable probe (green star) containing a complementary bioorthogonal group $(\mathrm{Y})$ thus allowing to selectively label the biomolecule of interest in a complex mixture of biomolecules (purple circle). 


\subsection{The major bioorthogonal reactions}

The name bioorthogonal ligation characterizes a reaction which is both very selective and which can be carried out in a biological system without interfering with the natural biochemical processes. Such a reaction has to meet many criteria to be bioorthogonal and ultimately, several degrees of bioorthogonality should be considered. The reaction must be biocompatible, meaning achievable under physiological conditions and with non-toxic reagents. The kinetics must be very favorable in order that (i) the coupling can be realized before efflux of the reagents by the biological system and (ii) the reagents can be used at low concentrations. The yield must be high and the products must be inert and stable in order to avoid interactions with the biological medium. ${ }^{10}$

The main bioorthogonal reactions also meet criteria of the click chemistry concept developed during a similar period of time. "Click Chemistry" is a term that was introduced by the group of Sharpless in 2001 including the following criteria: (i) A click chemistry reaction must be able to be applied and easily adapted in many fields (including pharmaceutical and materials chemistry); (ii) the reaction must be high yielding; (iii) the reaction must be quick; (iv) if generated, by-products, must be non-reactive, non-toxic, and easily removable (without chromatography); (v) the reaction must be stereospecific; (vi) the reaction conditions should be simple and easy to implement; (vii) solvents should be non-toxic (ideally in an aqueous medium). ${ }^{11}$ However, it should be kept in mind that some click chemistry reactions will not meet the bioorthogonality criteria essential for biological applications, while some bioorthogonal reactions will not meet the $c l i c k$ chemistry criteria, such as the Staudinger ligation.

Fig. 2 summarizes the main bioorthogonal reactions used in metabolic labeling studies so far including the Staudinger-Bertozzi ligation, the $\mathrm{Cu}$-catalyzed azide-alkyne cycloaddition $(\mathrm{CuAAC})$, the strain-promoted [3+2] alkyne-azide cycloaddition (SPAAC) and the inverse electron demand Diels-Alder reaction (IEDDA) also called tetrazine ligation.

Inspired by the Staudinger reduction, ${ }^{12}$ the group of Bertozzi team proposed in 2000 the design of a novel aromatic phosphine allowing a rearrangement of the intermediate aza-ylide into a stable compound via the intramolecular formation of an amide bond..$^{13}$ The mechanism of action was evidenced thereafter. ${ }^{14}$ The major drawbacks of this reaction are oxidation of phosphine (in air or by metabolic enzymes) and its slow reaction rate.

In the 1960s, Huisgen presented a systematic description of 1,3-dipolar cycloadditions, also called Huisgen cycloadditions, between two unsaturated reagents to form five-membered heterocycles. ${ }^{15}$ Huisgen studied the reaction between an azide and an alkyne giving rise to a disubstituted 1,2,3-triazole, described for the first time by Michael in $1893 .{ }^{16}$ Based upon a pericyclic mechanism, this [3 + 2]

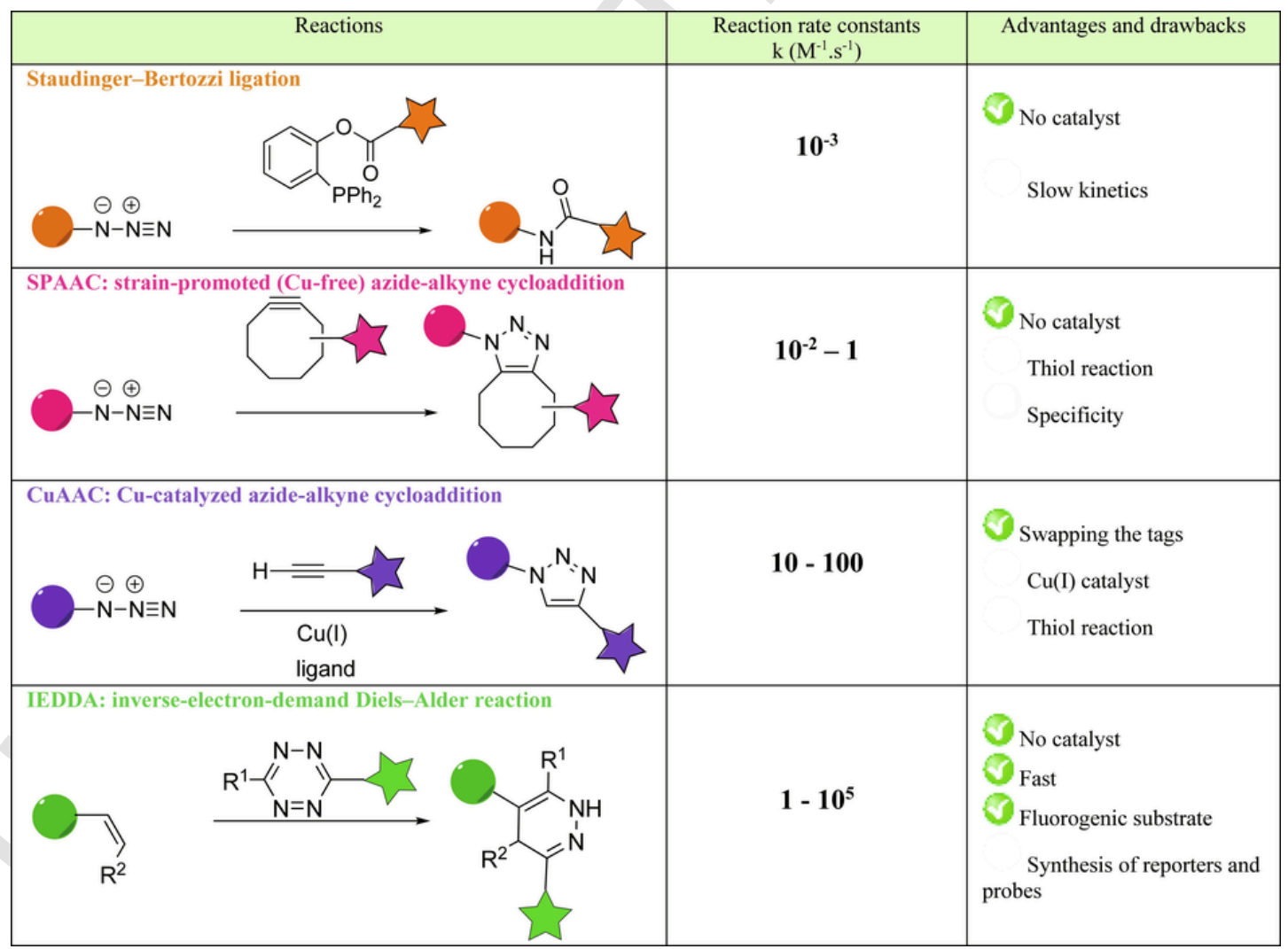

Fig. 2 Most used cycloaddition reactions for bioorthogonal labeling of biomolecule according to their range of rate constants and main advantages and challenges. 
cycloaddition does not however meet the requirements of bioorthogonal click chemistry as outlined above. Indeed, this reaction requires reflux heating, the use of organic solvents and it suffers from slow kinetics (reaction time of several hours or even days). In addition, the reaction is not regioselective: a mixture of 1,4- and 1,5-disubstituted triazoles is obtained. In 2002, two different teams showed that copper(I) can be used as a very efficient catalyst for azide-alkyne cycloaddition. The advantages of this copper-catalyzed reaction are multiple: the reaction is up to a million times faster than the thermal reaction, no heating is necessary and the coupling can be performed in an aqueous medium compatible with biological systems. ${ }^{17,18}$ In 2013, the group of Fokin proved the involvement of two copper atoms in the molecular mechanism of CuAAC reaction through experiments combining the use of isotopic metals and calorimetry. ${ }^{19}$ Even if the two copper atoms first coordinate to distinct sites on the alkyne group, the reaction proceeds via an intermediate in which both become equivalent and exchangeable as shown by Bertrand and his group. ${ }^{20}$

One of the advantages of CuAAC is the possibility to freely choose between azide and alkyne, the tag to be introduced on the chemical reporter or on the probe. The kinetics of the reaction is quite high, with an apparent rate constant $k$ between 10 and $100 \mathrm{M}^{-1} \mathrm{~s}^{-1} .{ }^{21}$ The main drawback of this reaction is the use of copper(I) as a catalyst. By catalyzing the formation of reactive oxygen species (ROS) including hydroxyl radicals, copper(I) could be toxic to living systems. ${ }^{22}$ However, the in situ generation of $\mathrm{Cu}$ (I) from $\mathrm{Cu}$ (II) and the addition of tetravalent $\mathrm{Cu}(\mathrm{I})$ ligands allows this drawback to be overcome in some situations. ${ }^{23,24}$

While the $\mathrm{CuAAC}$ reaction is to date probably the most widely used bioorthogonal reaction for the selective labeling of biomolecules it is not, however, "fully" bioorthogonal due to the potential cytotoxicity of $\mathrm{Cu}(\mathrm{I})$ ions which differs in each case study. To address this drawback, an adaptation of the CuAAC has been developed.

The modification (SPAAC), is a cycloaddition between an azide and a cyclic alkyne, usually a cyclooctyne or an heteroatom-containing analog, without copper. Initially, this reaction was first mentioned by Blomquist and Liu who observed an "explosive reaction" between a phenyl azide and a cyclooctyne. ${ }^{25}$ The reaction was then re-explored by the group of Bertozzi in 2004 as a new bioorthogonal ligation which can be carried out in a biological medium under physiological conditions and without catalyst. ${ }^{26}$ The team exploited the SPAAC for the first time for the labeling of biomolecules present in cell lysates and directly in living cells. ${ }^{26}$ As for the CuAAC, the SPAAC reaction must be effective under biological conditions where the azide-tagged biomolecule is present in relatively small amounts and the intrinsic kinetics must be high. Between 2006 and 2010, many derivatives of the initial cyclooctyne probe were designed and synthesized with the aim of improving reactivity and/or solubility in aqueous media. ${ }^{27-36}$ Since no catalyst is involved, reactivity can be increased by structural means, such as increasing the planarity of the cyclooctyne or hetero-cyclooctyne ring, which imparts additional strain on the alkyne. A good example of this is a biarylazacyclooctynone derivative (named BARAC) that includes an endocyclic amide and whose reactivity surpassed that of all the other probes developed so far for SPAAC, with a rate constant of about $1 \mathrm{M}^{-1} \mathrm{~s}^{-1}$. ${ }^{35}$ However, even though the SPAAC reaction offers better compatibility in a biological environment than the CuAAC reaction (due to the absence of copper catalysis), the reaction has lower kinetics. In addition, its reactive groups are no longer interchangeable: the steric hindrance of the cycloalkyne moiety could disrupt metabolic pathways, and must be included in the chemical structure of the detection probe and not in the chemical reporter. Moreover, some cyclooctyne derivatives have shown poor stability, as well as potential reactivity with biological nucleophiles such as thiols.$^{37}$ Nevertheless, thanks to the numerous optimizations of SPAAC coupling kinetics, this ligation has become one of the most widely used reactions with CuAAC for bioorthogonal labeling. Since 2004, it has been exploited in a wide range of biological applications for the detection of proteins, ${ }^{38}$ glycans, ${ }^{28}$ lipids ${ }^{39}$ or nucleic acids. ${ }^{40}$

Interestingly, Fox and co-workers reported a reaction based on the IEDDA reaction between an $s$-tetrazine and trans-cyclooctene (TCO). ${ }^{41}$ During this reaction, the tetrazine is converted to the dihydropyrazine cycloadduct, the only byproduct being dinitrogen, upon a retro-[4+2] cycloaddition. This tetrazine ligation is faster than all other bioorthogonal reactions known to date when performed with a trans-cyclooctene, but can also be performed with less strained alkene, albeit with lower kinetics.

Thanks to these developments in bioorthogonal chemistry, the applications of metabolic labeling have increased over years, and some of them will be presented in other chapters of these series. The current chapter will focus on carbohydrate-derived chemical reporters developed in the last years for the metabolic labeling of the bacterial cell envelope. We present approaches to their chemical synthesis and discuss the applications of these methods for both academic or applicative research. Strategies targeting other components of the bacterial envelope, including the peptide moiety of peptigoglycan ${ }^{42,43}$ or teichoic acids, ${ }^{44,45}$ have been developed, but will not be discussed here. Although the main objective of this chapter is the metabolic labeling by the chemical reporter strategy, some examples of the one-step labeling strategy with carbohydrates functionalized with detectable probes are also discussed.

\section{Glycans in the bacterial cell envelope}

The bacterial cell envelope defined as the structure that surrounds the cytosol is a multilayered architecture consisting of a variety of macromolecules. The cell envelopes of most bacteria fall into one of three major groups, depending on their structure: Gram-negative bacteria, Gram-positive bacteria, and mycobacteria (Fig. 3). The cell envelope is critical in many processes including resistance and protection against the environment, cell division, transport of molecules and cellular adhesion.

A large variety of glycans and glycoconjugates are found in the distinct structures of the bacterial envelope (Fig. 4). They provide shape, rigidity and mechanical strength to the cell, are involved in interaction with other bacteria and host cells, and in mycobacteria, they allow for anchoring of specific lipids responsible for impermeability of the membrane. They can be involved in virulence and pathogenicity, as well as confer stealth properties to certain bacterial strains.

Peptidoglycan (PG) is the major component of the cell wall of almost all bacteria conferring resistance to osmotic pressure and maintaining cell shape. ${ }^{46} \mathrm{PG}$ is an heteropolymer composed of linear glycan chains that are cross-linked by short peptides. The glycan chains alternate $N$-acetyl-glucosamine (GlcNAc) and $N$-acetyl-muramic acid (MurNAc) residues, linked by $\beta$ - $(1 \rightarrow 4)$ bonds. MurNAc is unique to bacteria. 


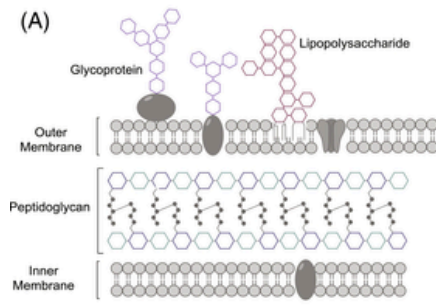

Gram-negative bacteria

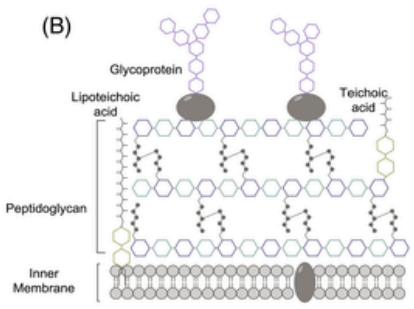

Gram-positive bacteria

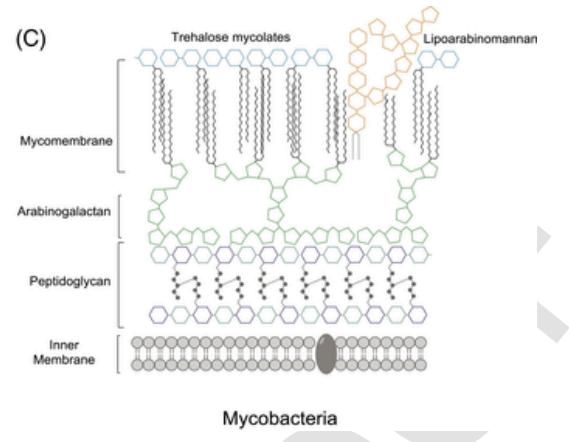

Fig. 3 Schematic representation of the structure of typical bacterial cell envelope (A) Gram-negative bacteria, (B) Gram-positive bacteria, (C) Mycobacteria (glycans structure are highlighted in color).

In Gram-negative bacteria, also called diderm-LPS, the envelope consists of an inner and an outer membrane separated by the periplasm occupied by a thin peptidoglycan layer. These bacteria are covered by a dense layer of lipopolysaccharides (LPS), which is the major component of the outer leaflet of their outer membrane. ${ }^{47}$ This glycolipid shows high structural variability between different bacterial species, but also between different strains belonging to the same species, and has been correlated to some extent with viability and virulence. The polysaccharidic part of this LPS consists of a large diversity of monosaccharidic components, including some common sugars such as glucose, galactose or sometimes fucose or $N$-acetyl-neuraminic acid, but also monosaccharides which are bacterial-specific such as L-glycero-D-manno-heptose (Hep) or 3-deoxy-D-manno-octulosonic acid (Kdo).

In Gram-positive, or monoderm, bacteria, the envelope consists of only one cell membrane surrounded by a thicker and multilayered peptidoglycan. It contains additional unique components named teichoic acids that are either covalently linked to the peptidoglycan or anchored to the cell membrane as glycolipids named lipoteichoic acids. ${ }^{48}$

Mycobacteria possess distinctive envelopes and are not classified according to the classical Gram-staining procedure, but can be classified as diderm-mycomembrane. The inner membrane is covered by a peptidoglycan layer and a unique arabinogalactan (AG) layer covalently linked to the peptidoglycan. Arabinogalactan is a polysaccharide composed predominantly of D-galactofuranosyl (Galf) and D-arabinofuranosyl (Araf) moieties. AG provides an anchor for unique high molecular weight fatty acids called mycolic acids (MAs), that are very-long (C30-C90) $\alpha$-branched $\beta$-hydroxylated fatty acids, thus giving rise to the mycoloyl-arabinogalactan-peptidoglycan complex (mAGP). The bilayer of the outer membrane is characterized by the presence of mycolic acids which are linked to arabinogalactan for the inner leaflet whereas in the outer leaflet, MAs are linked to trehalose as trehalose monomycolates (TMMs) or trehalose dimycolates (TDMs). Trehalose is a singular non-reducing disaccharide absent from vertebrates and formed from two glucose units linked through their anomeric position ( $\alpha$-D-glucopyranosyl- $\alpha$-D-glucopyranoside).

This unusual outer membrane usually referred to as the mycomembrane (MM) is unique to the order of Corynebacteriales and is responsible for the low permeability of the envelope thus contributing to natural resistance to various antimicrobial compounds and enhancing persistence in host environments. ${ }^{49,50}$

Mycobacteria also possess mannosyl-phosphatidyl-myo-inositol-based glycolipids (PIM) and related lipoglycans, i.e. lipomannan (LM) and lipoarabinomannan (LAM) which are anchored in the inner and outer membranes by their phosphatidyl-D-myo-inositol unit. ${ }^{51,52}$ LAM is composed of a D-mannan core branched by arabinofuranosyl side chains and a terminal D-arabinan moiety that can be covalently capped by various structures. ${ }^{53}$

Some strains also synthesize glycoproteins that are presented on their cell surfaces. ${ }^{54}$ Glycosylation of bacterial proteins has several functions including the maintenance of protein conformation and stability, modulating pathogenicity, increasing resistance against proteolytic digestion, antigenicity, immunogenicity and involvement in host-adhesion. ${ }^{55}$ They possess variably modified polysaccharides depending on the bacterial species. Several mannoproteins (secreted or not) in Mtb have been identified to play an important role in pathogenesis. It should be underlined here that such kind of mannosylation is clearly different from that found in the mannosylated glycans of human cells. ${ }^{56-58}$ Furthermore, some unusual monosaccharide components such as pseudaminic acid (Pse), legionaminic acid (Leg), bacillosamine (Bac) derivatives, DATDH (2,4-diacetimido-2,4,6-trideoxyhexose), or $N$-acetyl-D-fucosamine (FucNAc) have been identified in different bacterial species (Fig. 4).

Cell envelope synthesis takes place continuously. Thus, probes using the metabolic pathways involved in the construction of these glycan-based molecular architectures are powerful tools to address biological issues.

\section{Carbohydrate-derived chemical reporters for the study of the bacterial cell envelope}

Bioorthogonal chemical reporters developed for the metabolic labeling of bacterial cell glycans can be divided into four main families based on their localization in the cell envelope: those targeting the peptidoglycan, the glycoproteins, the lipopolysaccharide, or the mycomembrane. This section describes the structures, the synthetic routes and the applications of glycan-based probes developed so far for the study of bacteria. 

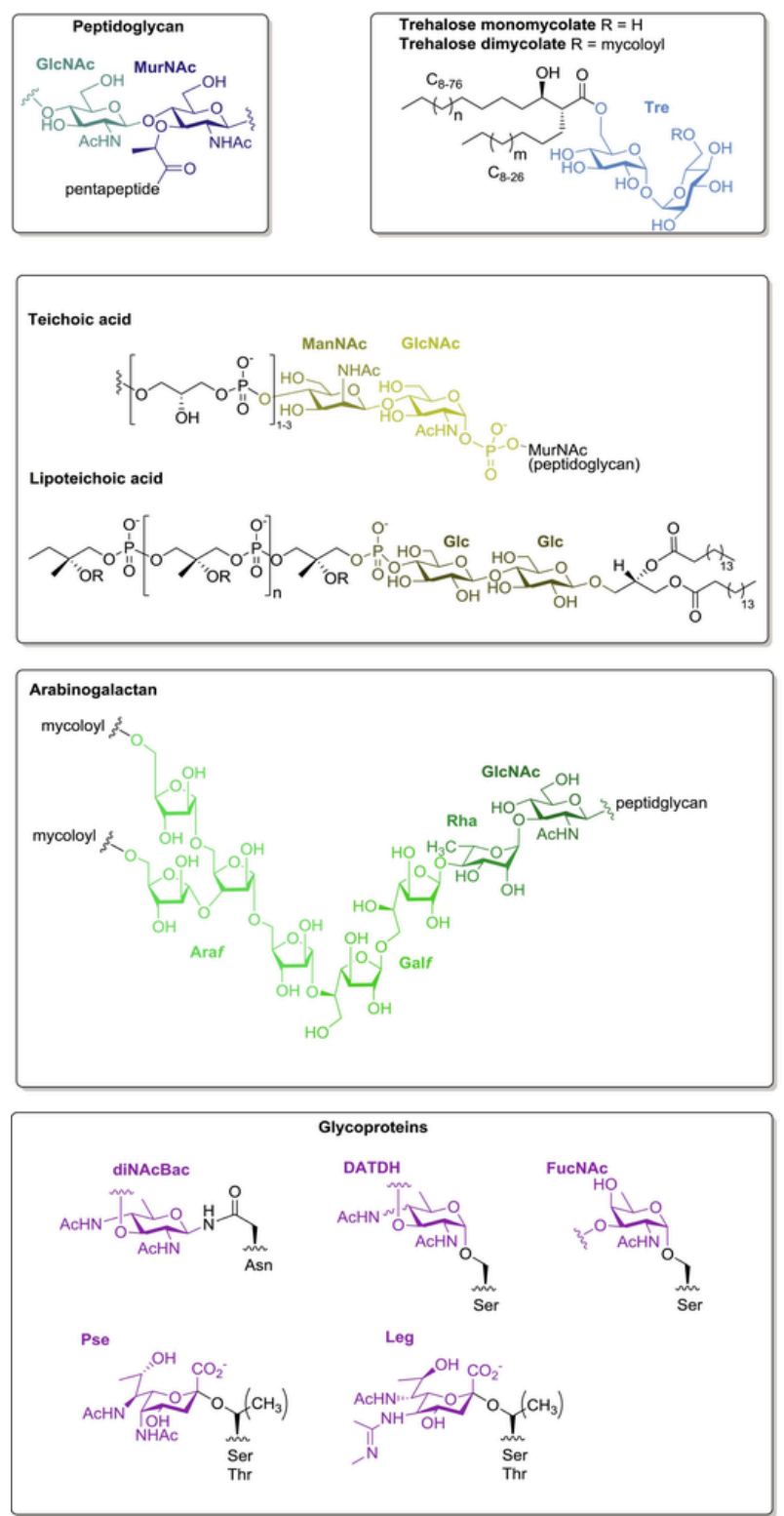

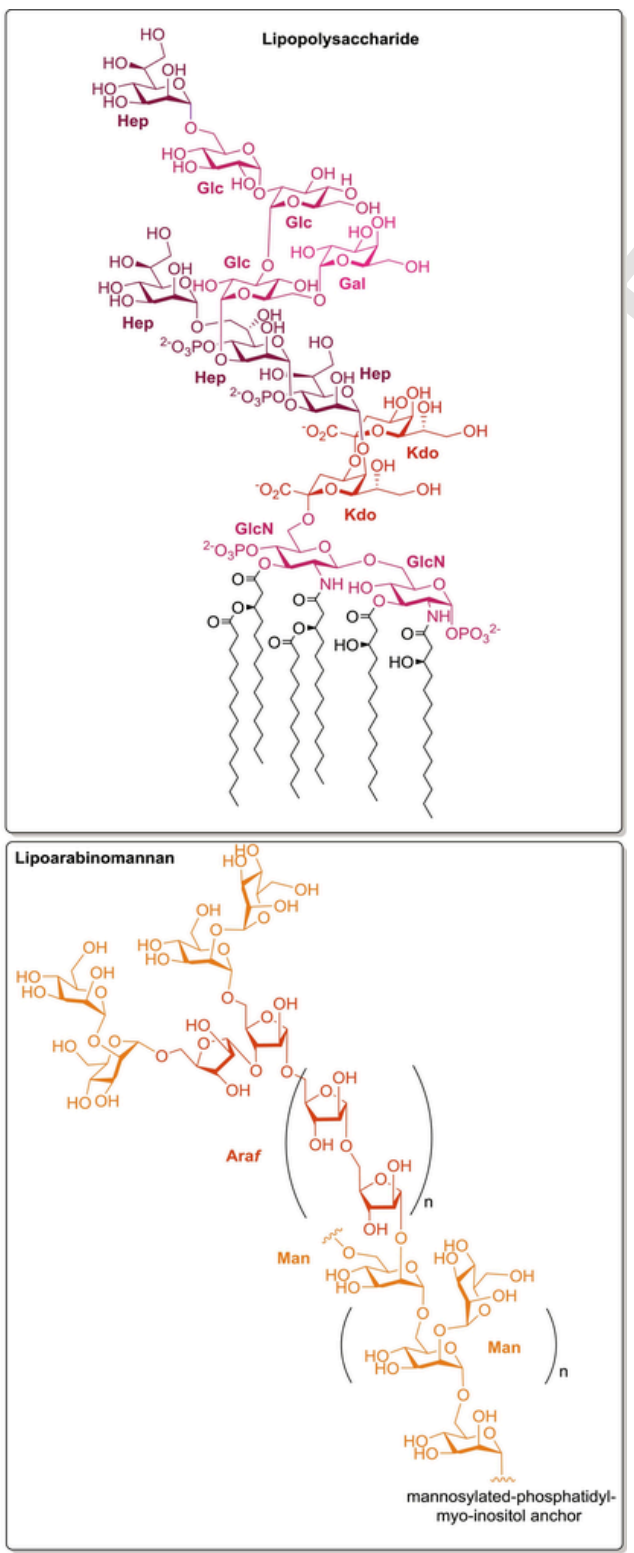

Fig. 4 Chemical structures of the main glycans found in bacterial cell envelope classified according to the type of specific glycoconjugates found in the different bacterial species (glycans structure are highlighted in color; the color code follows the same rules as those in Fig. 3). The lipoarabinomannan and the arabinogalactan are presented in a simplified representation. Abbreviations: GlcNAc: $N$-acetyl-glucosamine; MurNAc: $N$-acetyl-muramic acid; Tre: trehalose; ManNAc: $N$-acetyl-mannosamine; Rha: rhamnose; Araf: arabinofuranose; Gal: galactose; Galf: galactofuranose; Man: mannose; Hep: L-glycero-D-manno-heptose; Kdo: 3-deoxy-D-manno-octulosonic acid; GlcN: glucosamine; Leg: legionaminic acid; $P s e$ : pseudaminic acid; FucNAc: $N$-acetyl-D-fucosamine; DATDH: 2,4-diacetimido-2,4,6-trideoxyhexose; diNAcBac: $N, N^{\prime}$-diacetylbacillosamine.

The design of such metabolic probes needs several issues to be addressed, including:

- understanding and mastering the pathways of entry, transport and bioavailability when they are known. These questions are essential, but often difficult to address. A commonly used option to favor entry of polar carbohydrates into eukaryotic cells is to use their per-acetylated version and rely on intracellular non-specific esterase activity to recover the deacetylated probe. This strategy might however lead to the unexpected $S$-glycosylation of cysteines, ${ }^{59}$ and the efficiency of bacterial esterase activity in such a context is not proven. ${ }^{60,61}$ Entry becomes even more challenging for charged sugars, sugar nucleotides and phosphorylated derivatives unless a specific pathway can be diverted for probe transport. ${ }^{62}$ Some studies have employed partial permeabilization of the bacterial membranes to allow probe entry ${ }^{63}$;

- avoiding location of the bioorthogonal chemical function on a position which would preclude normal continuation of biosynthesis; 
- making judicious choices regarding the different metabolic and catabolic pathways that could disseminate the bioorthogonal reporter within molecules not belonging to the targeted pathway.

It should also be noted than some labeling strategies involve genetic modification of the targeted bacteria in order to modify their metabolism and force probe incorporation, while other strategies directly target wild type bacteria. Both strategies are meaningful, but potential applications are obviously different. Fig. $\mathbf{5}$ attempts to summarize the major elements to keep in mind when designing probes for metabolic labeling.

\subsection{Chemical reporters for the carbohydrate backbone in peptidoglycan}

Several probes have been reported to label the highly conserved polysaccharide portion of the peptidoglycan (PG) either through the de novo biosynthetic pathway or through a salvage pathway. PG biosynthesis is a complex process involving many enzymatic reactions that occurs in three distinctive compartments of bacteria namely the cytoplasm (synthesis of nucleotide precursors), the inner leaflet of the inner membrane (synthesis of lipid-bound intermediates), and the outer membrane (final polymerization and crosslinking reactions). ${ }^{64-66}$ The first cytoplasmic stage of this biosynthesis involves the conversion of UDP- $N$-acetyl-glucosamine (UDP-GlcNAc) into UDP- $N$-acetyl-muramic acid (UDP-MurNAc) whose lactate moiety allows for anchoring of the pentapeptide in the later steps to yield Park's nucleotide (Fig. 6). Once the monophospho-MurNAc-pentapeptide moiety is transferred onto the membrane acceptor undecaprenyl phosphate (C55-P) by MraY forming Lipid I, this latter molecule is glycosylated by MurG introducing a GlcNAc and forming Lipid II that is transferred to the periplasm and represents the final monomeric building block in PG biosynthesis before polymerization (Fig. 6).

Metabolic labeling of peptidoglycans by carbohydrate has been first performed by the Nishimura group in 2002, using UDP-muramyl pentapeptide analogs functionalized by fluorescein (UDP-MPP-FITC) or the reactive keto group of a levulinoyl moiety (UDP-MPP-Lev) that can be further functionalized with a Alexa 488 hydrazide through $N$-acyl-hydrazone formation (Fig. 7) ${ }^{63}$

After incubation of diverse bacteria with these compounds, metabolic incorporation could be shown by fluorescence of the extracted cell wall as well as fluorescence imaging in the case of monoderm bacteria. Further remodeling of the bacterial surface through the incorporation of oligomannosides led to bacteria with engineered adhesion properties toward a concanavalin A coated surface. ${ }^{67}$ Labeling the peptidoglycan of diderm LPS bacteria such as E. coli proved more tedious and required preliminary permeabilization of the outer membrane. In order to avoid tedious and difficult to scale-up synthesis, Nishimura's group then developed a second family of probes, ${ }^{68}$ based on derivatives of GlcNAc-1P, which is a metabolic precursor of UDP-MurNAc. The authors were able to identify 3,4,6-triacetyl- $N$-levulinoyl-D-glucosamine-1-phosphate (GlcLev-1P) as an effective probe for peptidoglycan labeling of Gram-positive bacteria. In addition to easier synthetic access, peracetylation allowed for improved delivery of the probe due to an increased membrane permeability and efficient intracellular deacetylation by non-specific esterase activity.

During bacterial cell wall remodeling, some peptidoglycan fragments are released and potentially recycled through a salvage pathway in the cytoplasm to form new UDPG-MurNAc precursors. Hence, free $N$-acetyl-muramic acid can be recycled as a UDP-sugar by using a kinase (AmgK) and an uridyltransferase (MurU) (Fig. 6). In 2017 and 2018, Grimes' team developed muramic acid derivatives functionalized either on the $\mathrm{N}$-acetyl group or on the lactic acid moiety, and capable of being incorporated in PG via this peptidoglycan recycling pathway. ${ }^{69,70}$ The $N$-acetyl derivatives, named MurNAz, MurNAlk (Fig. 7) proved to be processed through the MurNAc salvage

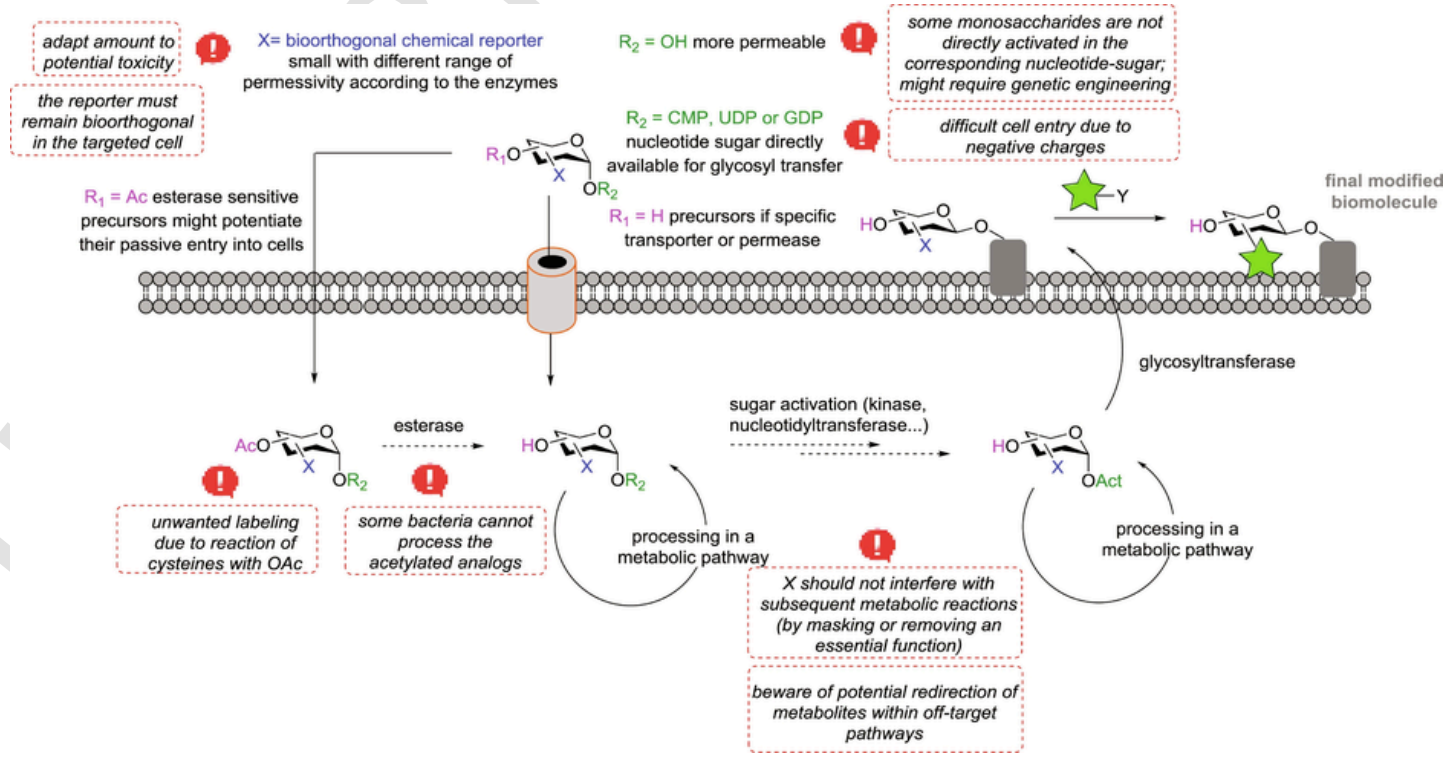

Fig. 5 Designing a new probe for metabolic labeling might seem straightforward. However, this figure schematically summarizes a few recommendations that might prove useful when embarking on such a journey. 


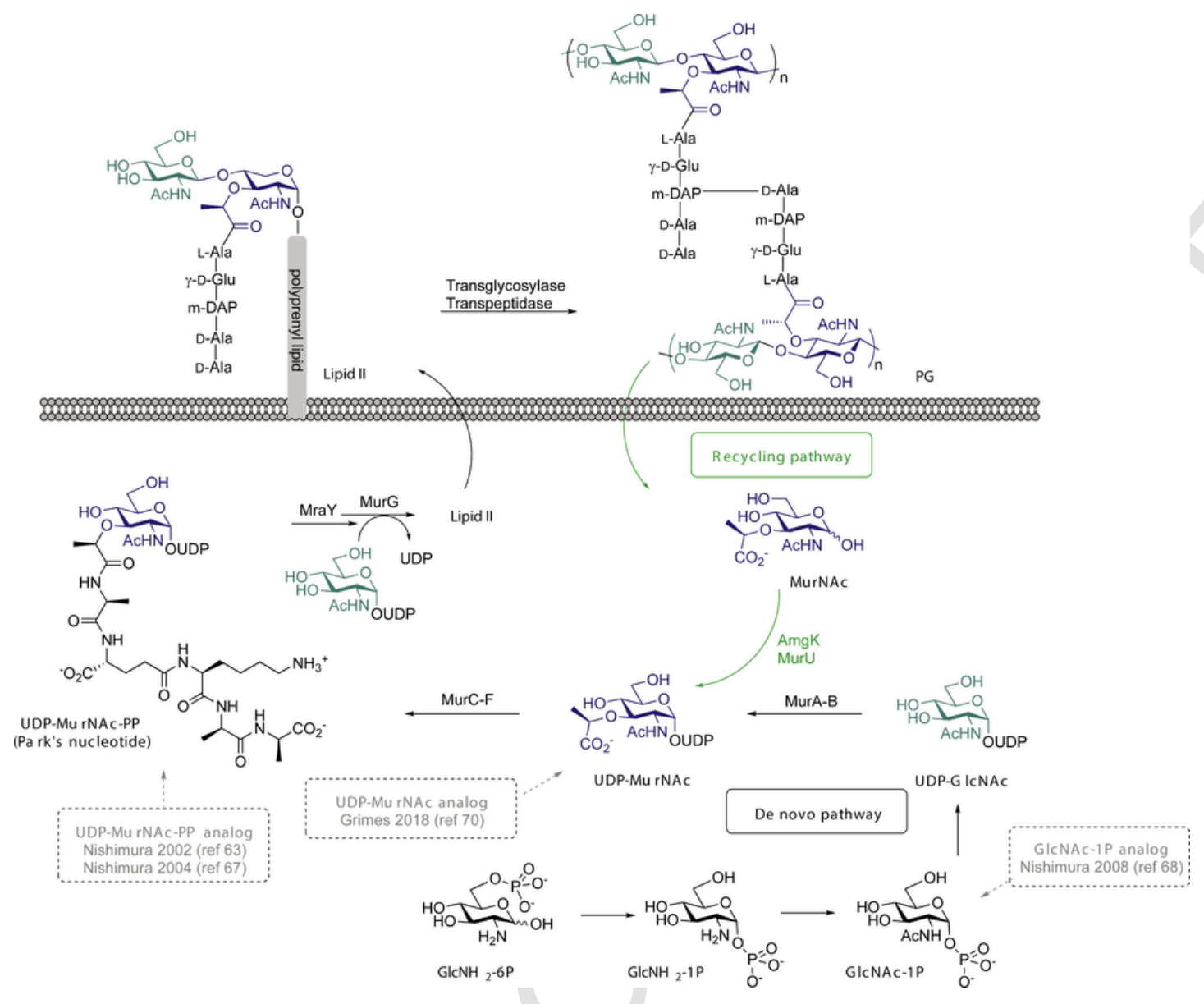

Fig. 6 Schematic representation of the biosynthesis of peptidoglycans highlighting the de novo pathway, which is general to all bacteria (in black), and the recycling pathway (in green), which is only present in specific species (e.g. Pseudomonas putida) or can be introduced in genetically engineered strains in order to allow peptidoglycan labeling. UDP-MurNAc can be produced from UDP-GlcNAc through enzymes MurA and MurB, and is then converted in UDP-MurNAc pentapeptide (Park's nucleotide) through MurC-F enzymes. Alternatively, it can be produced from degraded peptidoglycan by salvaging MurNAc trough enzymes AmgK and MurU.

pathway by using bacterial strains genetically modified to express this pathway, or Pseudomonas putida, a species naturally expressing this salvage pathway. These probes allowed visualization of whole cell Gram positive and Gram negative bacteria notably using super-resolution microscopy revealing features of PG. ${ }^{69}$ Labeled bacteria were also visualized within macrophages allowing tracking of bacterial invasion. Interestingly, specific labeling of PG could be used to further characterize the innate immune responses toward MurNAc-containing PG fragments. In another study, a larger library of 2- $N$-functionalized MurNAc probes was synthesized including multiple bioorthogonal moieties such as cyclopropene and tetrazine for IEDDA conjugation, or a fluorescein for one-step labeling. Only the MurNTetraz analog bearing a tetrazine moiety was assayed for labeling and resulted in poor fluorescence signal, and degradation of cell morphologies.

The 3-azido-lactic acid modified MurNAc derivative, i.e. MurLAz, was designed based on the fact that in some bacteria, 2- $N$-deacetylated PG is found ${ }^{71}$ and some of them including $M t b$ can modify their $2-N$-acetyl group into $N$-glycolyl to evade immune response. ${ }^{72}$ Thus, the reactive handle could be lost once introduced in the PG if the unnatural acyl group is hydrolyzed. MurLAz proved to be efficient to label only the PG septal division ring of $E$. coli cells genetically engineered to express the recycling pathway and knock out MurQ, an enzyme which cleaves the lactic acid moiety of MurNAc-6P.

The first series was obtained through alkylation of a conveniently-protected derivative of glucosamine to introduce lactic acid, followed by acylation to install either an azido or an acetylenic reporter (Scheme 1). During the course of this study, a chemoenzymatic synthesis was developed to produce the UDP derivatives from the 2- $N$-functionalized MurNAc probes. By using the bacterial cell wall recycling enzymes (i) AmgK, an anomeric kinase, to produce the monophosphate derivative and (ii) MurU to generate the UDP-sugar, several UDP-based probes were obtained. UDP-MurNAz was used for labeling of Lactobacillus acidophilus.

Obtention of the second series of metabolic reporters relied on late stage introduction of an azido group onto the lactic acid moiety (Scheme 2). 

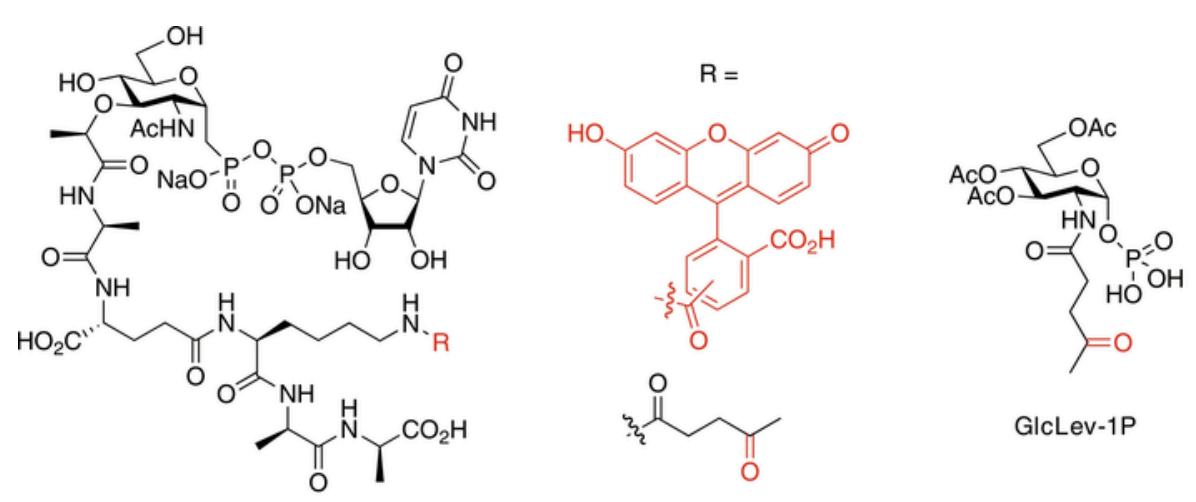

UDP-MPP-LeV UDP-MPP-FITC

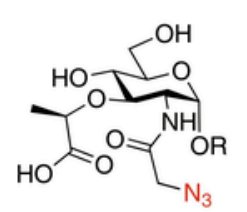

$\mathrm{R}=\mathrm{H} ;$ MurNAz $\mathrm{R}=$ UDP; UDP-MurNAz<smiles>C#CCCC(=O)NC(OCC(C)O)C(O)COC(C)C(=O)O</smiles>

MurNAIk

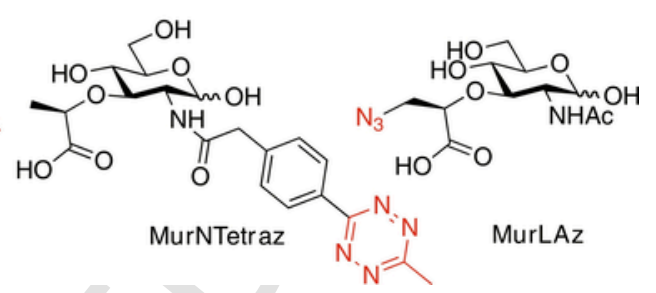

Fig. 7 (Top) Chemical structures of probes used by Nishimura to label peptidoglycans (Bottom) Functionalized muramic acid derivatives for peptidoglycan labeling.

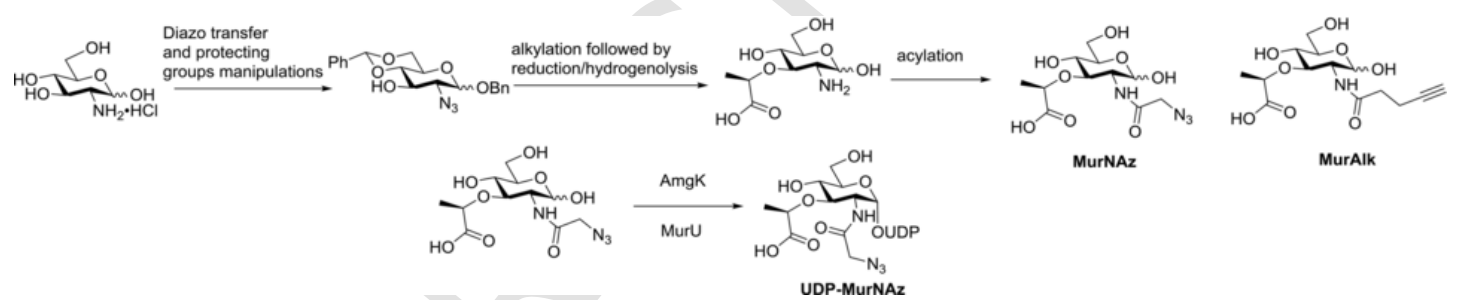

Scheme 1 Synthesis of muramic acid derivatives modified on the $N$-acetyl group.

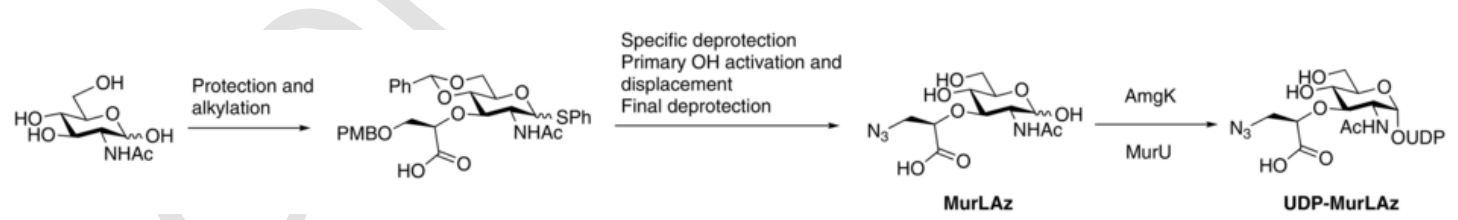

Scheme 2 Synthesis of muramic acid derivatives modified on the lactic acid moiety.

\subsection{Chemical reporters for glycoproteins}

Bacterial glycoproteins are generally obtained by glycosylation with non-redundant enzymes which are specifically devoted to this modification. In the case of species or strain-specific glycosylation, a series of enzymes are responsible for the biosynthesis of rare sugars, and metabolic labeling could target any of the metabolic intermediates in these pathways. ${ }^{73,74}$ For instance, ulosonic acids such as pseudaminic acid can be targeted via their immediate precursors as shown below. In this context, several original probes have been developed for metabolic labeling of specific bacterial glycoproteins (Fig. 8). 


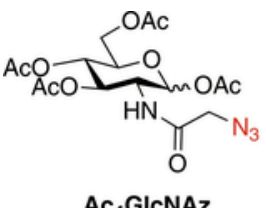

$\mathrm{Ac}_{4} \mathrm{GlcNAz}$

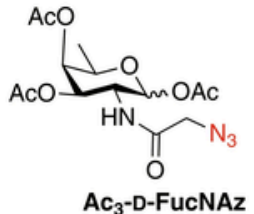

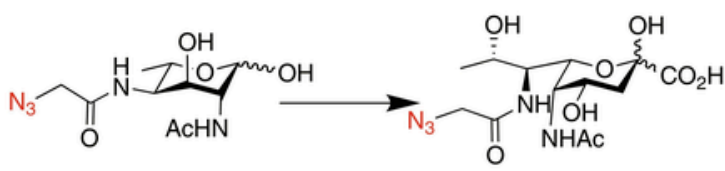

Pse5Ac7NAz

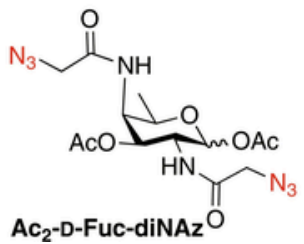<smiles>C#CC1OC(O)C(O)C(O)C1(O)O</smiles>

FucAl

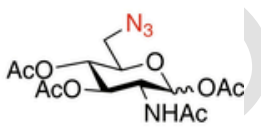

$\mathrm{Ac}_{3} \mathrm{GICNAC} \mathrm{N}_{3}$

Fig. 8 Some of the probes used to label bacterial glycoproteins.

The group of Dube's labeled glycoproteins of Helicobacter pylori using $\mathrm{Ac}_{4} \mathrm{GlcNAz}$ metabolic incorporation, followed by a Staudinger ligation reaction with a phosphine connected to a FLAG peptide (DYKDDDDK), and anti-FLAG antibodies. ${ }^{75}$ The same year, Logan and Tanner showed that it was possible to label the flagella glycoproteins of Campylobacter jejuni using an analog of

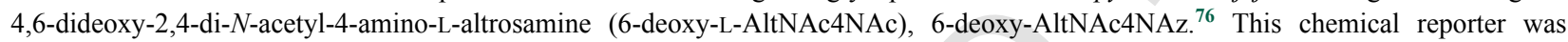
obtained through the use of bacterial enzymes in a combination of enzymatic and chemical transformations (Scheme 3).

Metabolic incorporation of this precursor of 5,7-di- $\mathrm{N}$-acetyl-pseudaminic acid was validated via Staudinger ligation incorporating a biotin.

In 2011, Wu's group used an alkyne derivative of L-fucose, FucAI, prepared from L-galactono-1,4-lactone following Wong's procedure (Scheme 4), ${ }^{77}$ to perform metabolic labeling of glycoproteins of bacteria (LPS diderms), ${ }^{78}$ followed by introduction of a biotin derivative through CuAAC, and eventually biotin-recognition by a fluorescent streptavidin.

In 2016, Kulkarni and Dube prepared a small library of azido sugars, including analogs or rare deoxy-amino-monosaccharides, and evaluated them in the labeling of glycoproteins from various pathogenic and symbiotic bacterial strains, paving the way to differential labeling of various bacterial cells. ${ }^{79}$ It should be noted that these molecules are analogs of monosaccharides that can also be coupled to other glycoconjugates such as LPS, or of their precursors.

Analogs of rare 2,4-diacetamido-2,4,6-trideoxy-D-galactose (DATDG-diNAc), were prepared via a double inversion of a bis-triflate, followed by azide reduction and acylation, while analogs of $N, N^{\prime}$-diacetyl-bacillosamine (Bac-diNAc) where obtained from the same bis-triflate, through sequential azide and nitrite introduction. Renewed triflylation of the axial hydroxy group resulting from spontaneous nitrite hydrolysis, followed by azide introduction, led to the expected product after azide reduction followed by acylation of the resulting amines (Scheme 5).

\subsection{Chemical reporters for lipopolysaccharides}

Lipopolysaccharides biosynthesis is a relatively elaborate process, involving numerous enzymes and transport through two membranes and the cell wall (Fig. 9). Initial steps happen in the cytosol and at the inner leaflet of the inner membrane, and involve the transformation

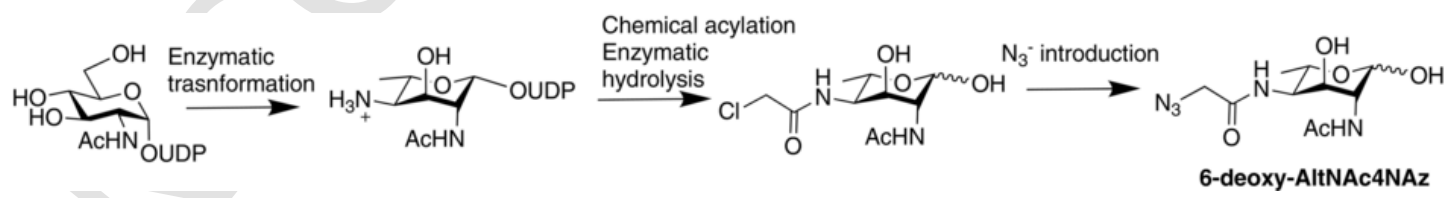

Scheme 3 Chemo-enzymatic synthesis of 6-deoxy-AltNAc4NAz.

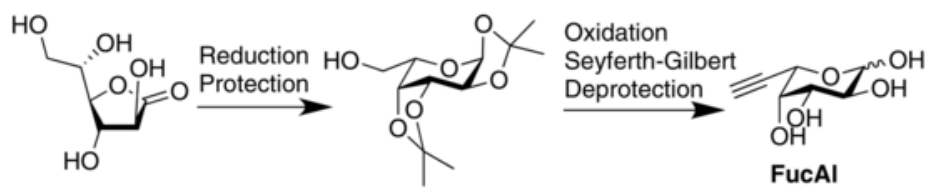

Scheme 4 Short synthesis of an alkyne derivative of L-fucose. 


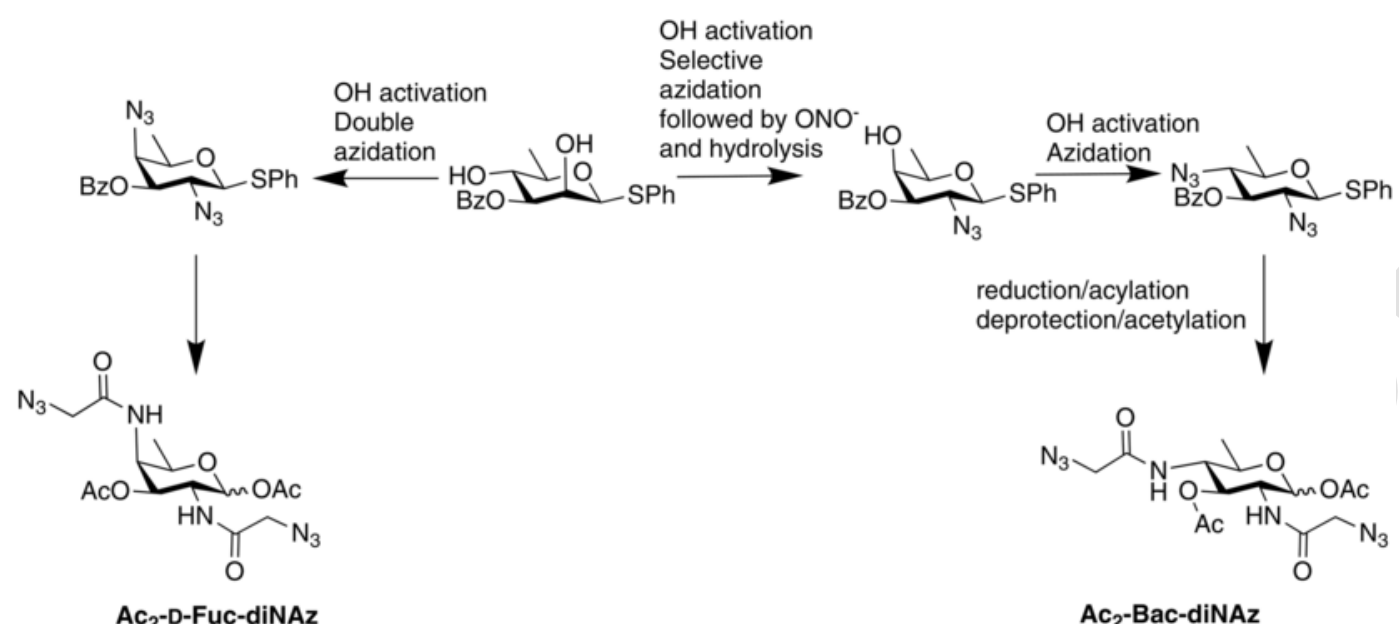

Scheme 5 Synthesis of probes derived from DATDG-diNAc and Bac-diNAc.

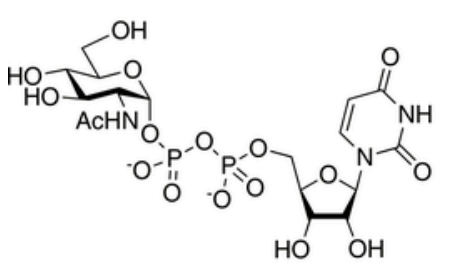

UDP-GICNAC
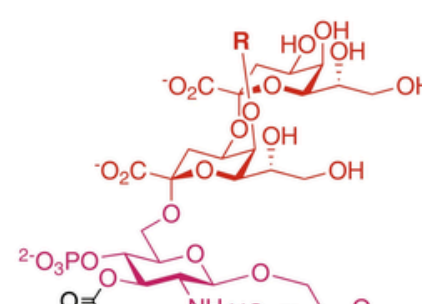
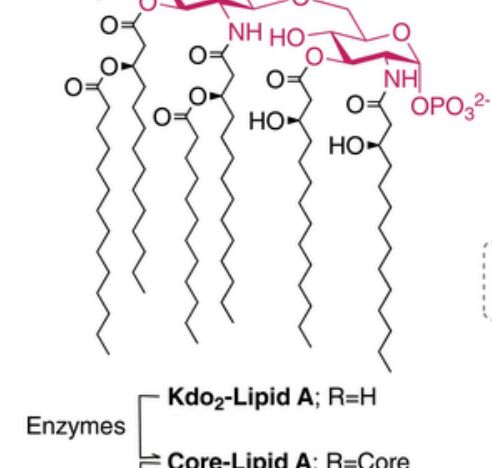

WaaL

$-\mathrm{Kdo}_{2}$-Lipid $\mathrm{A} ; \mathrm{R}=\mathrm{H}$

$\rightleftharpoons$ Core-Lipid A; R=Core

(periplasm) $\rightarrow$ LPS; R=Core- $\mathrm{O}$-antigen

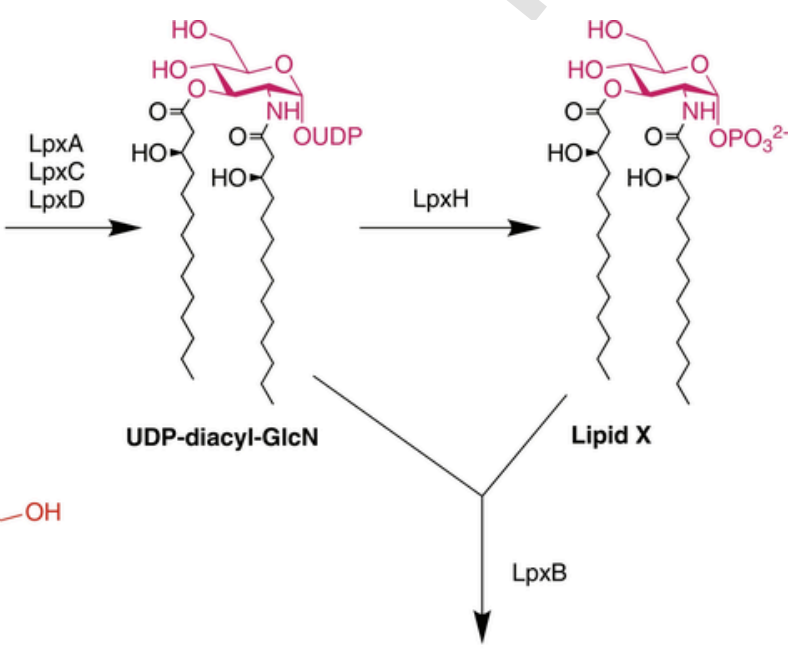

Fig. 9 Schematic representation of the biosynthesis of lipopolysaccharides. The core-lipid A is biosynthesized on the internal leaflet of the inner membrane, prior to transport to the outer leaflet where the $O$-antigen is transferred onto the core. 
of UDP-GlcNAc into UDP-diacyl-GlcN through the addition of two acyl chains, followed by hydrolysis leading to Lipid X. Condensation of UDP-diacyl-GlcN and Lipid X leads to the formation of disaccharide-1P, which is further acylated and phosphorylated, leading to Lipid $\mathrm{IV}_{\mathrm{A}}$. Incorporation of two Kdo units results in $\mathrm{Kdo}_{2}-\mathrm{Lipid} \mathrm{IV}_{\mathrm{A}}$, which is further acylated into $\mathrm{Kdo}_{2}-\mathrm{Lipid} \mathrm{A}$. This intermediate is then elaborated via construction of the core oligosaccharide, through the action of a series of enzymes, before core-Lipid A is transported to the outer leaflet of the inner membrane. The $O$-antigen repeating units are also elaborated on the cytosolic leaflet of the inner membrane in the form of an undecaprenyl phosphate conjugate, prior to being transported to the outer leaflet of this inner membrane, polymerized, and transferred to the core-Lipid A. The resulting nascent LPS still has to be transported to the inner leaflet of the outer membrane, and finally to the outer leaflet of this same outer membrane.

Preliminary studies targeting the LPS had been conducted by the group of Wang, who have shown the incorporation of modified fucose derivatives within the LPS of genetically engineered E. coli strains. Since L-fucose is not naturally present within E. coli LPS, (but only in the LPS of specific strains such as E. coli $\mathrm{O}^{80} 6^{80}$ ), and is normally not an intermediate in the normal "de novo" fucose pathway, these strains had been modified by genetic engineering to incorporate the so-called "salvage pathway", allowing the transformation of L-fucose and its derivatives into guanosine 5'-diphospho-fucose (GDP-Fuc) and analogs (Fig. 10). Incorporation of bioorthogonal chemical reporters allowed for labeling of the bacterial outer membrane. ${ }^{81}$

The next step targeted the lipopolysaccharide inner core of wild type bacterial strains, via the incorporation of an analog of Kdo, which is present in most Gram-negative bacteria, at the junction between lipid A and the polysaccharide. This synthetic analogs, 8-azido-8-deoxy-Kdo $\left(\mathrm{Kdo}_{\mathrm{N}}\right)$ was metabolically incorporated within the LPS of different bacterial species and strains (E. coli K12, E. coli O86, S. typhimurium, and L. pneumophila), whereas it was not incorporated by model Gram-positive bacteria (B. subtilis and $S$. aureus) or by $S$. oneidensis, a Gram-negative bacterium lacking Kdo. ${ }^{82} \mathrm{Kdo}-\mathrm{N}_{3}$ had been synthesized in an expeditious fashion starting from D-arabinose, the primary alcohol of which had been activated in the form of a tosylate and displaced by the azide anion (Scheme 6). Condensation with sodium oxaloacetate followed by decarboxylation led to the expected product. ${ }^{83}$ Extension of this labeling approach, for the incorporation of biotin at the bacterial surface allowed for enrichment of bacterial samples, using streptavidin-coated magnetic beads. ${ }^{84}$

A similar approach was developed targeting a metabolic precursor of legionaminic acid (Leg) a monosaccharide specifically present within Legionella pneumophila's lipopolysaccharide. Legionaminic acid is biosynthesized (Fig. 11) from UDP- $N, N^{\prime}$-diacetyl-bacillosamine, transformed into 2,4-diacetamido-2,4,6-trideoxy-D-mannopyranose by an hydrolyzing 2-epimerase. An aldolase transforms this intermediate into $N, N^{\prime}$-diacetyl-legionaminic acid (Leg5Ac7Ac), which is further activated to form CMP-Leg5Ac7Ac.

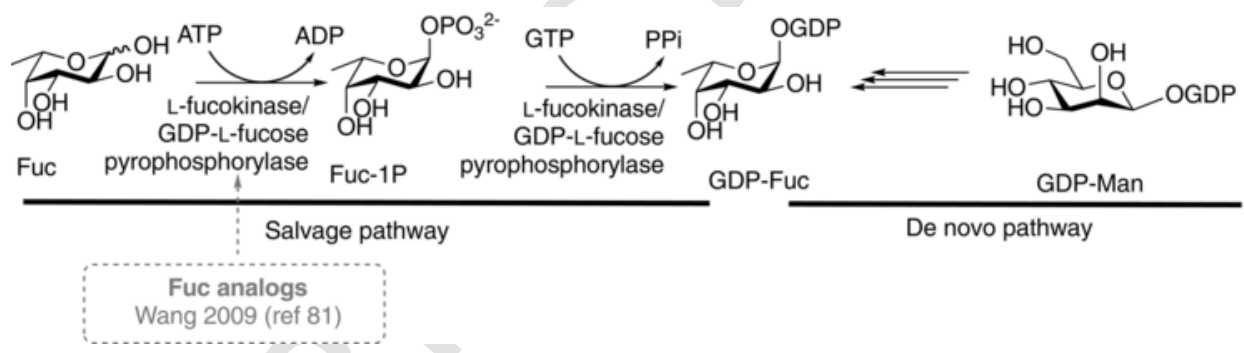

Fig. 10 Simplified representation of the de novo and salvage pathways for L-fucose biosynthesis.

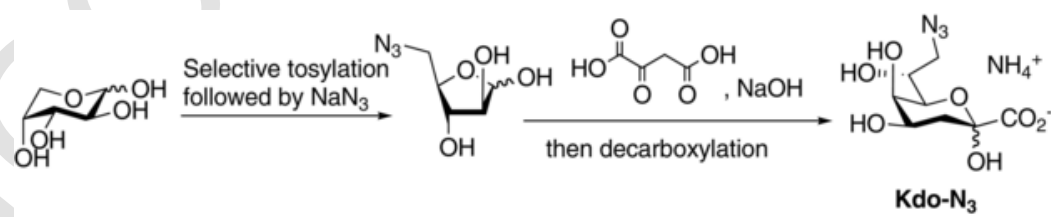

Scheme 6 Bioinspired synthesis of Kdo- $\mathrm{N}_{3}$.

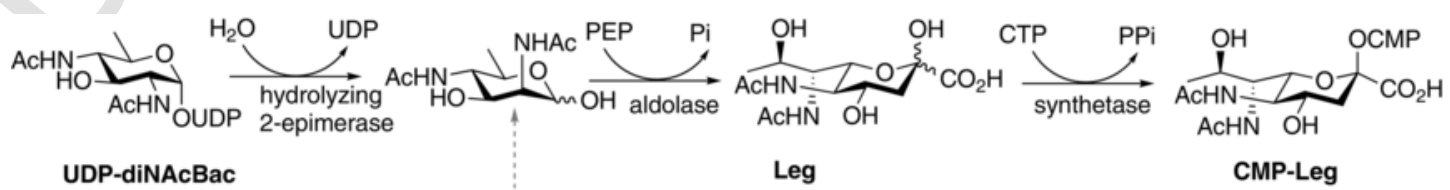

Leg precusor analog
Vauzeilles 2014 (ref 61)

Fig. 11 The legionaminic acid (Leg) biosynthetic pathway. 
This strategy allowed for the detection of L. pneumophila in bacterial samples and proved to be the first example of species identification using metabolic glycan labeling. ${ }^{61}$ The azido-derivative of the Leg precursor was prepared from D-galactose (Scheme 7), and involved selective benzoylation using Taylor's conditions, followed by the introduction of acetamido-groups through a bis inversion with azido anion, reduction and $\mathrm{N}$-acetylation, followed by deprotection. Activation of the primary alcohol via mesylation and displacement with azide resulted in the expected product after final deprotection.

In a similar strategy, $\mathrm{Li}$ and coworkers ${ }^{85}$ developed a synthetic approach toward 4,6-dideoxy-AltNAc4NAz and 4,6-dideoxy-AltNAz4NAc, which were used in their peracetylated form as analogs of precursors of pseudaminic acid (Pse) to label the $O$-antigen of LPS of specific Pse-containing strains of Pseudomonas aeruginosa, Acinetobacter baumannii, and Vibrio vulnificus.

The synthesis started by the published ${ }^{86}$ transformation of L-allo-threonine into a thioester which could after Fukuyama reduction, temporary masking of the aldehyde in the form of an olefin, protecting groups manipulations, ozonolysis and further adjustment of protecting groups lead to the expected products (Scheme 8).

\subsection{Chemical reporters for the mycomembrane}

Over the last decade, several bioorthogonal chemical reporters have been developed to study the dynamics of mycomembrane components. Most of them are trehalose derivatives applied to metabolically label mycobacteria-specific glycolipids TMM and TDM in the cell wall. ${ }^{87}$ Furthermore, few examples of probes designed to detect cell wall arabinosylation, were also recently designed but the way by which the labeling occurs in $M t b$ is still elusive. ${ }^{88}$

Trehalose is an essential highly abundant metabolite in Mycobacterium tuberculosis and in most of mycobacteria. In mycobacteria, trehalose is synthesized from several carbon sources but can also be imported. Free trehalose serves as a carbohydrate storage molecule and as a stress protectant. Trehalose is also an important component of cell wall glycolipids (TMM and TDM) in the outer membrane and is involved as carrier in mycolic acid processing. The $M t b$ trehalose-based glycolipids have immunomodulatory functions and are involved in the interaction with infected host cells. As trehalose is absent in mammalian cells, and can be supplied to mycobacteria exogenously, this makes it a good candidate for the design of analogs that can enter metabolic pathways in which trehalose is involved. In the past few years, several trehalose-based probes have been reported allowing the detection of the MM in live cells and the study of microbial physiology and pathogenesis through the metabolic labeling approach. Some of them are trehalose analogs containing detectable moieties (Fig. 12A), and others are functionalized with bioorthogonal chemical reporter groups (Fig. 12B).

\subsubsection{Trehalose-based probes synthesis}

Trehalose is a non-reducing disaccharide with a $\mathrm{C}_{2}$-symmetry consisting of two glucose moieties in a 1,1 - $\alpha, \alpha$-linkage. The synthesis of the described trehalose-based probes relies mainly on either stereoselective 1,1- $\alpha, \alpha$-glycosylation reactions between two functionalized and protected glucose units or desymmetrization of natural trehalose as inexpensive starting material using regioselective protection and deprotection steps to differentiate the eight hydroxyl groups. Besides chemical synthesis, chemoenzymatic synthesis were also reported allowing the preparation of trehalose-based probes from a synthetic functionalized glucose unit and commercially available UDP-glucose avoiding the time-consuming protection/deprotection steps. The synthetic accesses to various trehalose-based analogs or conjugates was recently reviewed by Kulkarni ${ }^{89}$ and the following is an overview of trehalose-based probes syntheses in the context of metabolic labeling.
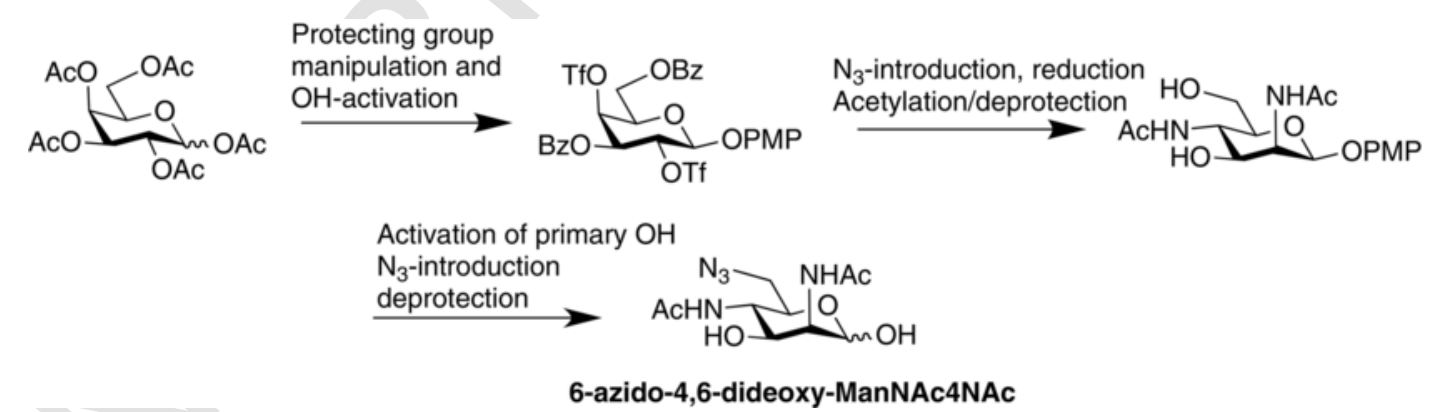

Scheme 7 Synthesis of 6-azido-4,6-dideoxy-ManNAc4NAc, an analog of the legionaminic acid metabolic precursor.

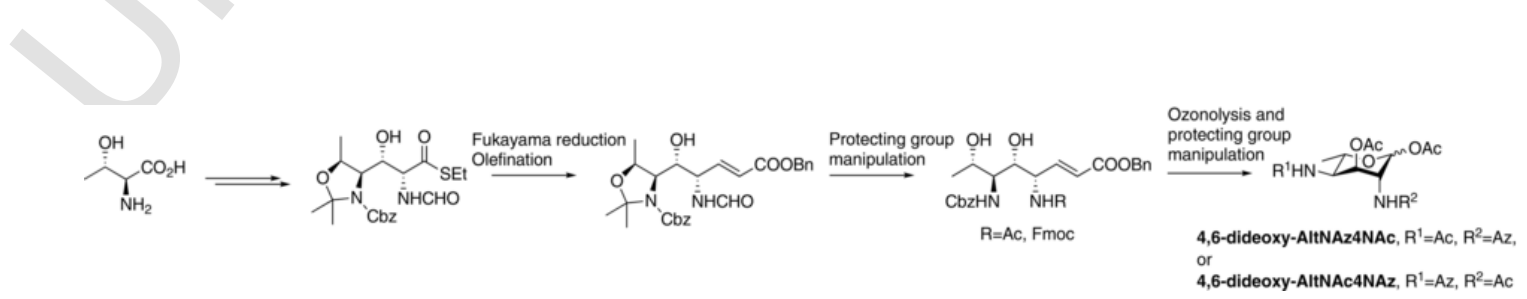

Scheme 8 Synthesis of 4,6-dideoxy-AltNAc4NAz and 4,6-dideoxy-AltNAz4NAc. 
(A)
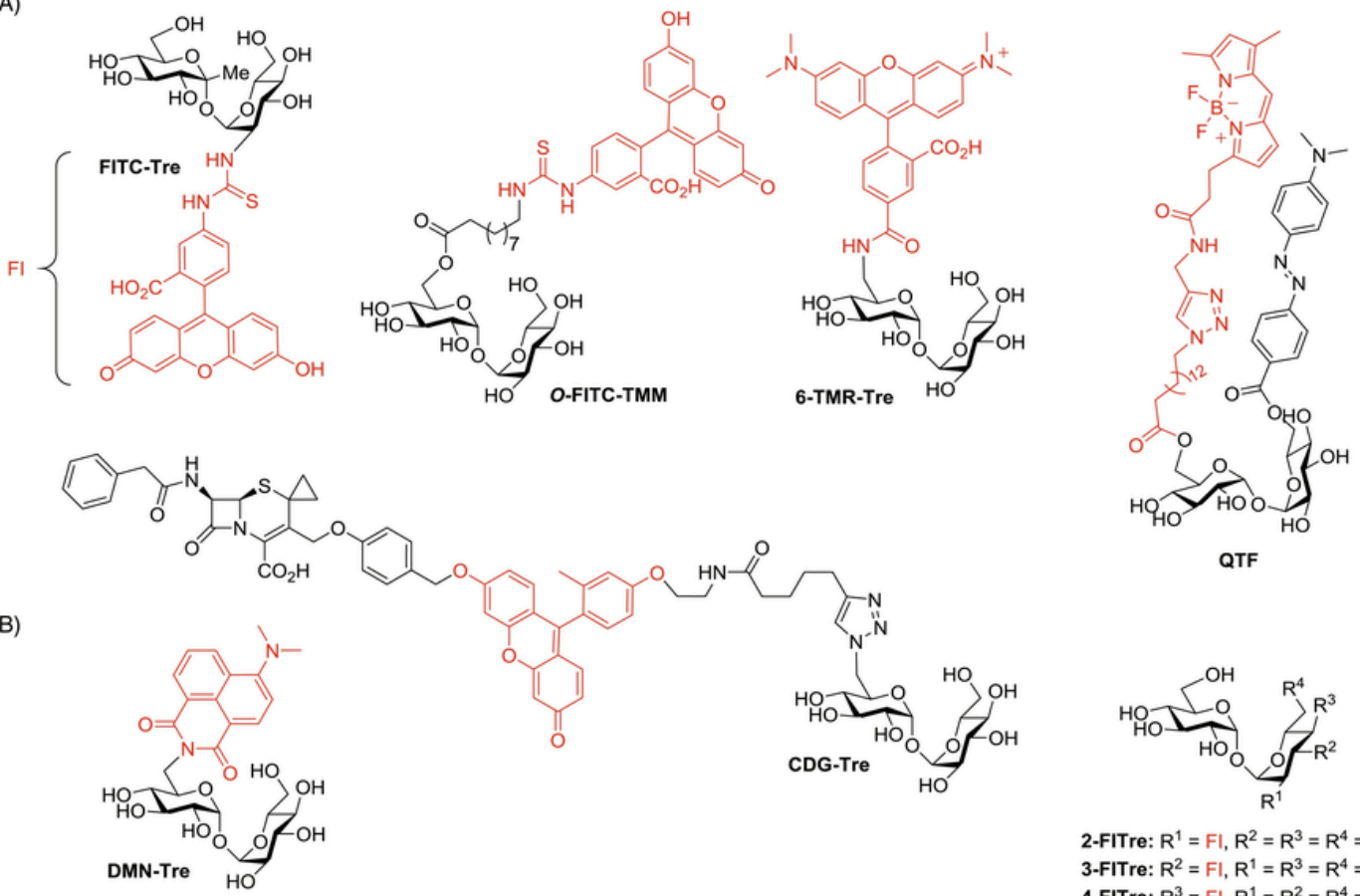

QTF

(B)

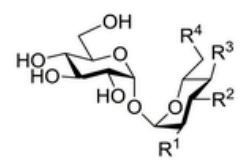

2-FITre: $\mathrm{R}^{1}=\mathrm{FI}, \mathrm{R}^{2}=\mathrm{R}^{3}=\mathrm{R}^{4}=\mathrm{OH}$ 3-FITre: $R^{2}=F I, R^{1}=R^{3}=R^{4}=O H$ 4-FITre: $\mathrm{R}^{3}=\mathrm{FI}, \mathrm{R}^{1}=\mathrm{R}^{2}=\mathrm{R}^{4}=\mathrm{OH}$ 6-FITre: $R^{4}=\mathrm{FI}, \mathrm{R}^{1}=\mathrm{R}^{2}=\mathrm{R}^{3}=\mathrm{OH}$

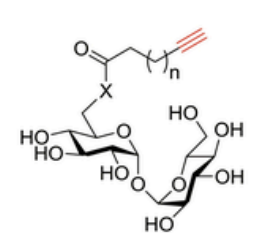

N-Alk-TMM: $X=N H, n=3$ O-Alk-TMM-C5: $X=O, n=1$ O-Alk-TMM-C5: $X=O, n=1$
O-Alk-TMM-C7: $X=0, n=3$ O-Alk-TMM-C7: $X=O, n=3$
O-Alk-TMM-C11: $X=O, n=7$
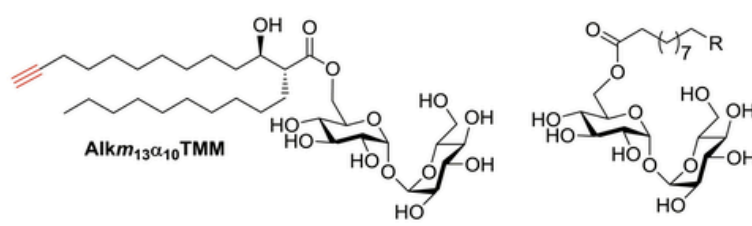

$$
\mathrm{TCO}=\text { s. }^{\mathrm{h}} \mathrm{N}^{\mathrm{O}} \mathrm{O}
$$

O-Az-TMM-C10: $R=N_{3}$

O-TCO-TMM: $\mathrm{R}=\mathrm{TCO}$

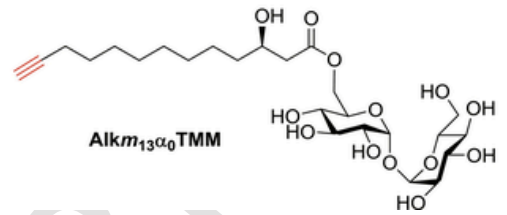

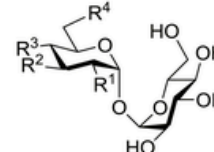

2-TreAz: $R^{1}=\mathrm{N}_{3}, \mathrm{R}^{2}=\mathrm{R}^{3}=\mathrm{R}^{4}=\mathrm{OH}$

3-TreAz: $R^{2}=N_{3}, R^{1}=R^{3}=R^{4}=O H$ 4-TreAz: $R^{3}=N_{3}, R^{1}=R^{2}=R^{4}=O H$ 6-TreAz: $R^{4}=N_{3}, R^{1}=R^{2}=R^{3}=O H$

Fig. 12 Chemical structures of trehalose-based probes for mycobacteria labeling. Trehalose analogs containing detectable moieties (A) and trehalose analogs functionalized with bioorthogonal chemical reporter groups (B).

In 2011, the groups of Davis and Barry described the synthesis of the first collection of trehalose-based probes, including the key reporter FITC-Tre, and their utilization to label mycobacteria cell wall. ${ }^{90}$ FITC-Tre was prepared starting from a known ketose ${ }^{91}$ and a glucosamine derivative ${ }^{92}$ using the $\alpha, \alpha$-glycosylation approach developed by Ikegami ${ }^{93}$ and governed by the additional anomeric methyl group, leading to a trehalose core with the expected 1,1- $\alpha, \alpha$-linkage. After de- $O$-acetylation and hydrogenolysis, treatment of the resulting free amine with fluorescein-isothiocyanate (FITC) led to FITC-Tre (Scheme 9).

In 2012 Bertozzi reported a mycomembrane labeling study using four different azido-trehaloses referred to as 2-, 3-, 4- and 6-TreAz. ${ }^{94}$ In this report, the challenging 2- and 3-TreAz were synthesized after selective functionalizations of a common desymmetrized intermediate prepared according to Wallace and Minnikin (Scheme 10). ${ }^{95} 6$-TreAz was prepared according to Hannessian ${ }^{96}$ and $4-$ TreAz was obtained by de- $O$-benzoylation of the known per- $O$-benzoylated-4-TreAz. ${ }^{97}$ In further studies, the four TreAz were also derivatized in new fluorescent probes 2-, 3-, 4- and 6-FITre, ${ }^{98} 6$-TMR-Tre ${ }^{99}$ and the solvatochromic dye DMN-Tre ${ }^{100}$ by the same group after reduction of the azido moieties and ligation to fluorescein carboxytetramethylrhodamine or reaction with dimethylaminonaphthalic anhydride, respectively.

Very recently, the new dye CDG-Tre, targeting two Mycobacterium tuberculosis enzymes (i.e. BlaC and Ag85) was reported by Rao starting from 6-TreAz. ${ }^{101}$ In this probe, a fluorescein derivative quenched by a cephalosporin residue is conjugated to trehalose (Scheme 11). 

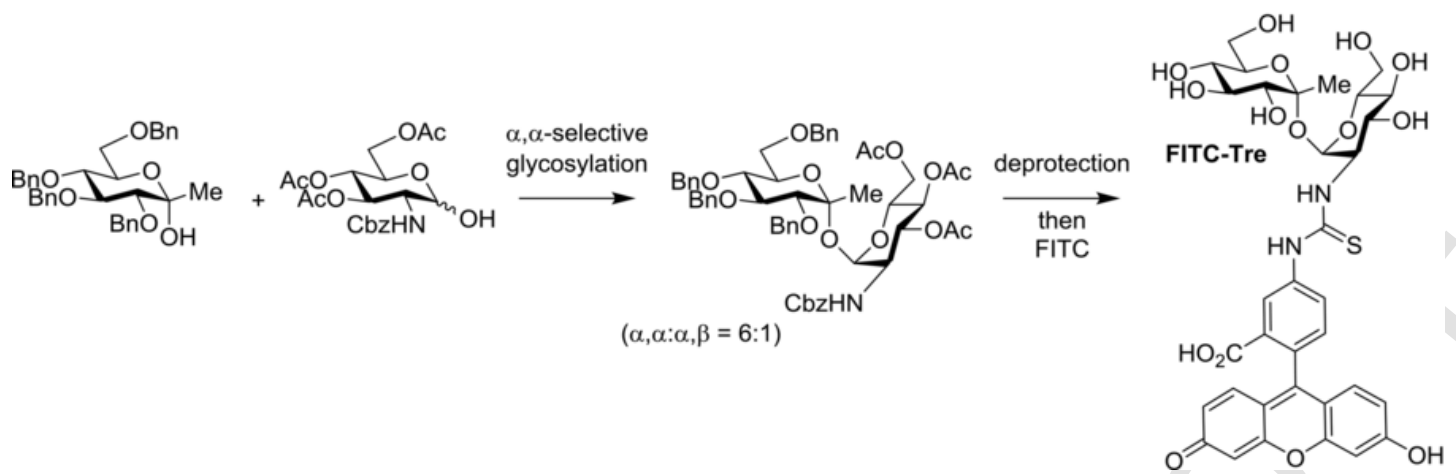

Scheme 9 Access to FITC-Tre.

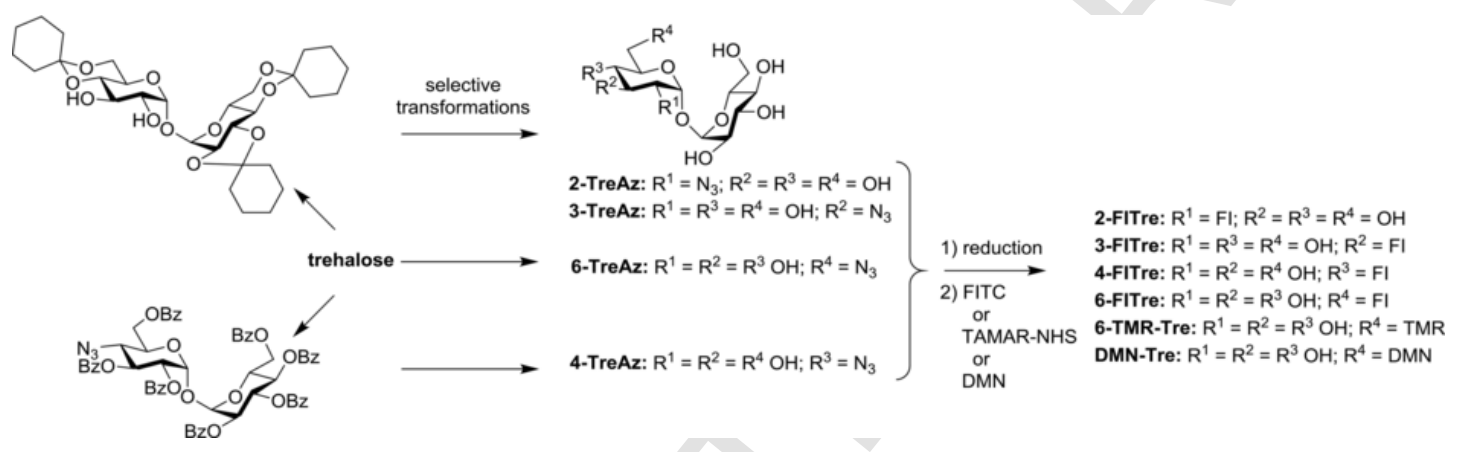

Scheme 10 Access to 2-, 3-, 4-, and 6-TreAz; 2-, 3-, 4-, and 6-FITre; 6-TMR-Tre and DMN-Tre.

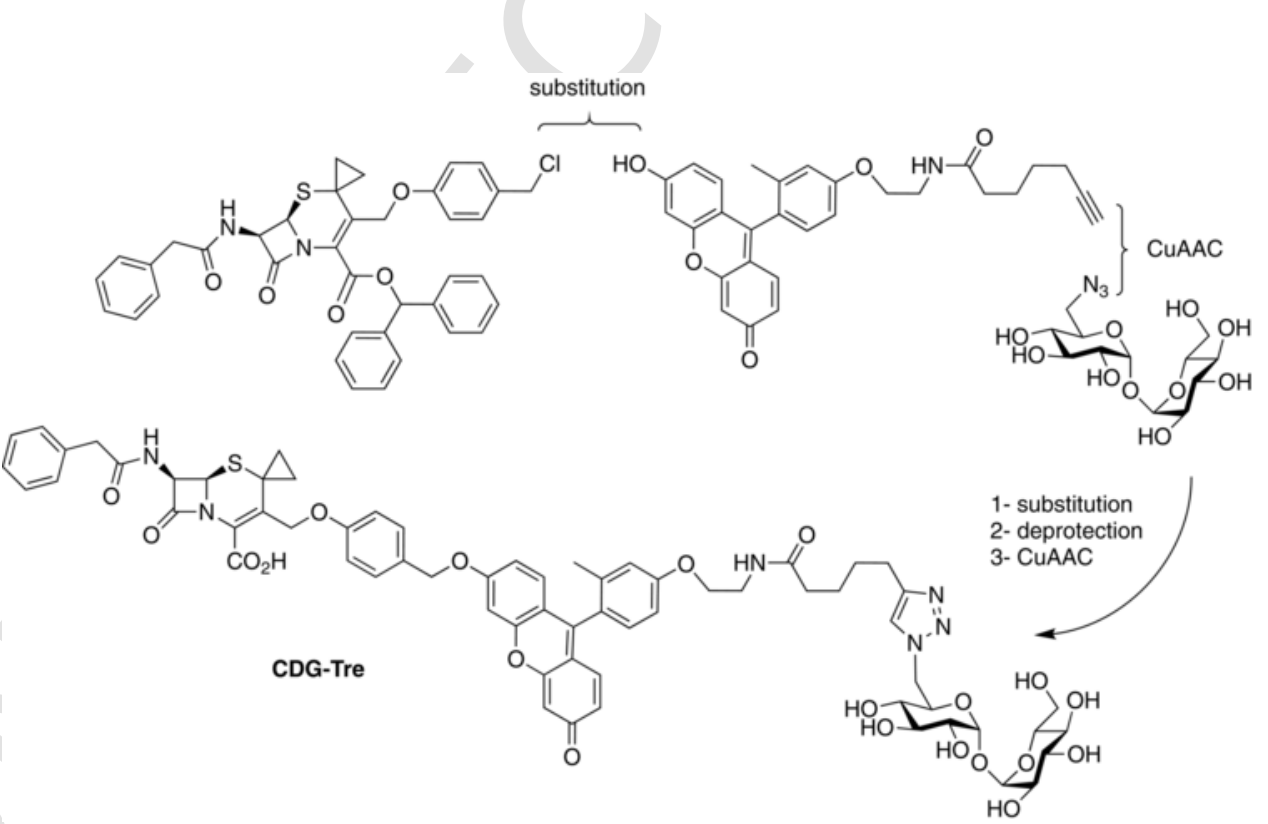

Scheme 11 Access to the dual targeting CDG-Tre probe.

In 2014 a chemoenzymatic approach, using trehalose synthase (TreT), allowed the rapid access to modified trehaloses starting from UDP-glucose and commercially available mono-modified glucose (Scheme 12). ${ }^{102}$ Thus, 2-, 3- and 6-azido trehalose were obtained in one step and good yields. This approach dramatically improves the access to such probes, since their chemical syntheses required many 

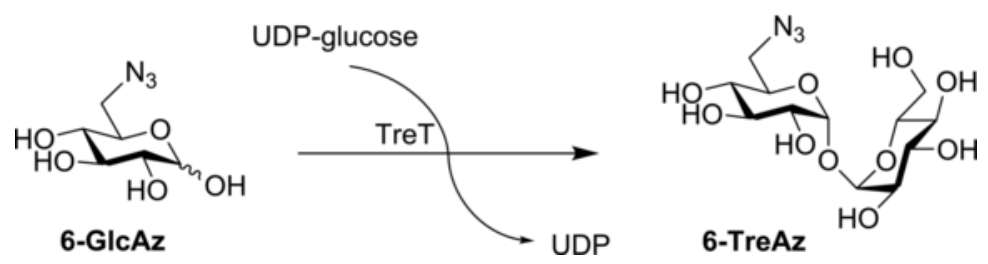

Scheme 12 Chemoenzymatic approach to azido-trehaloses.

selective transformations on native trehalose. It is noteworthy that this enzymatic approach failed with glucose modified in position 4 for the preparation of 4-modified trehalose. For these later the chemical synthesis remains efficient. Finally, the same approach was applied recently to UDP- $N$-acetyl- $\alpha$-D-glucosamine (UDP-GlcNAc) leading after deacetylation to trehalosamine (i.e. 2-amino-2-deoxy- $\alpha, \alpha$-D-trehalose), a direct precursor of 2-FITre and 2-TreAz after treatment with FITC and TfN $_{3}$ respectively. ${ }^{103}$

Additional probes, mimicking the mycoloyl donor TMM, were developed by the group of Swarts in order to target mycoloyltransferases in mycobacteria. ${ }^{104-106}$ In these probes, the complex structure of mycolic acids was replaced by a short linear alkyl chain bearing a bioorthogonal group (terminal alkyne, azide or TCO) or fluorescein at the end of the alkyl chain. This has considerably simplified access to new mycomembrane probes since these probes were easier to synthesize than compounds modified by a bioorthogonal function or fluorophore on trehalose core. They were prepared starting from the known symmetric hexa- $O$-silylated trehalose $\mathrm{e}^{107,108}$ by a mono esterification with an acyl chain of interest followed by deprotection under acid conditions (Scheme 13, top). The same synthetic approach was also used recently by Kiessling for the synthesis of the fluorogenic probe QTF (Quencher-Trehalose-Fluorophore). ${ }^{109}$ The hexa- $O$-silylated trehalose was in this case esterified successively at both $\mathrm{C} 6$ and $\mathrm{C} 6$ ' of trehalose with DABCYL-OH and 15-azidopentanoic acid. The di-esterified derivative was then coupled to a BODIPY and QTF was obtained after final deprotection (Scheme 13, bottom).

In 2019 Bourdreux and Guianvarc'h reported the synthesis of a trehalose monomycolate-based probe featuring for the first time the complex structure of mycolic acids i.e. an acyl chain with a $\beta$-hydroxyl and an $\alpha$-lipidic chain in an anti configuration. ${ }^{110}$ The synthesis started from a $\beta$-keto ester bearing a terminal alkyne group, and involved as key steps a Noyori enantioselective reduction and an anti-selective alkylation in order to introduce both the hydroxyl and the $\alpha$-chain in an anti relationship, mimicking the native structure of mycolic acids (Scheme 14).

\subsubsection{Trehalose-based probes applications}

Since the first study reported in $2011,{ }^{90}$ these probes have been extensively used for metabolic labeling in mycobacteria with several applications. Indeed, exogenous unnatural trehalose derivatives can be incorporated into mycomembrane either after transport of the disaccharide analogs in the cytoplasm or directly after processing by mycoloyltransferases of TMM analogs in the periplasm. In its natural form, trehalose acts as a mycolic acid carrier once the synthesis of this complex lipid has been completed by the polyketide synthase Pks13 (Fig. 13). It is converted into trehalose monomycolate in the cytoplasm and next, is transported into the outer membrane via a specific transporter. Once transported into the periplasm, TMM plays the role of a mycolate donor for several mycolate acceptors: $(i)$ the arabinogalactan (AG) layer, covalently linked to the peptidoglycan layer, (ii) another TMM to form trehalose dimycolate (TDM) or (iii)

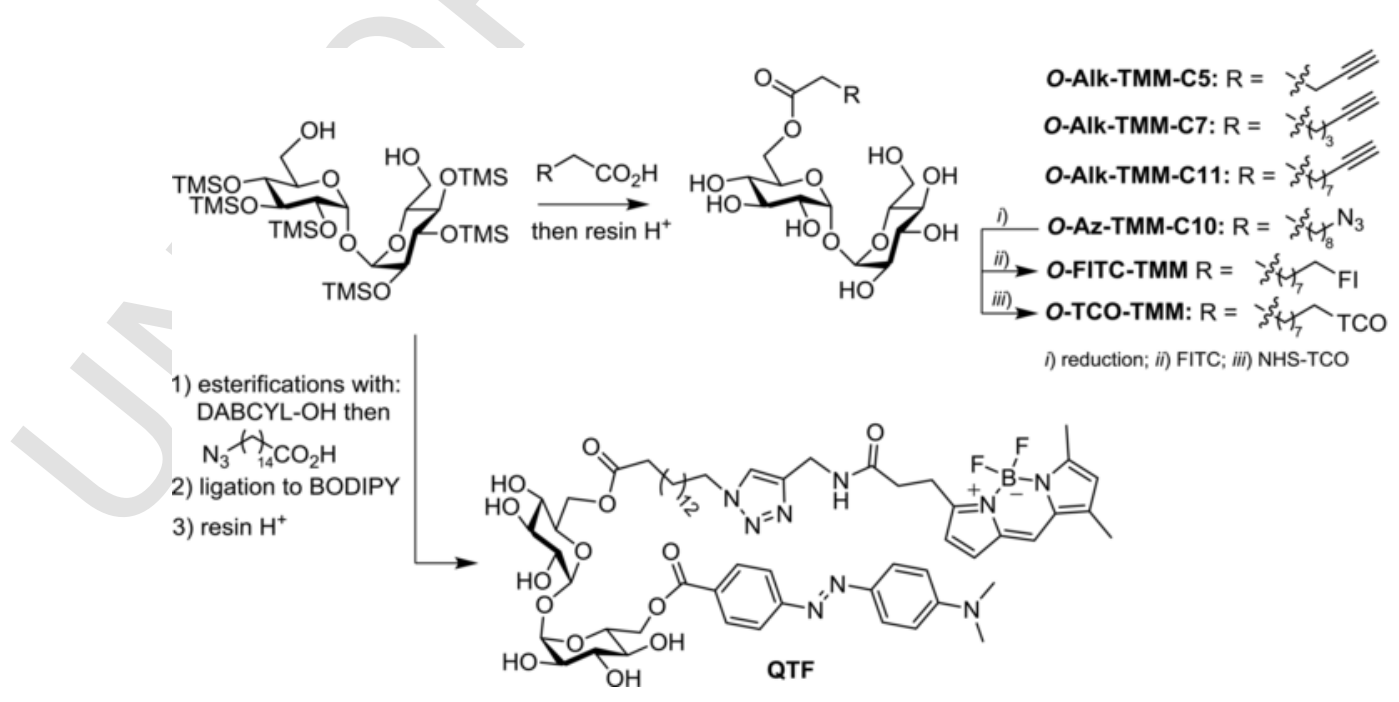

Scheme 13 Approach to unbranched acyl TMM-based and QTF probes. 


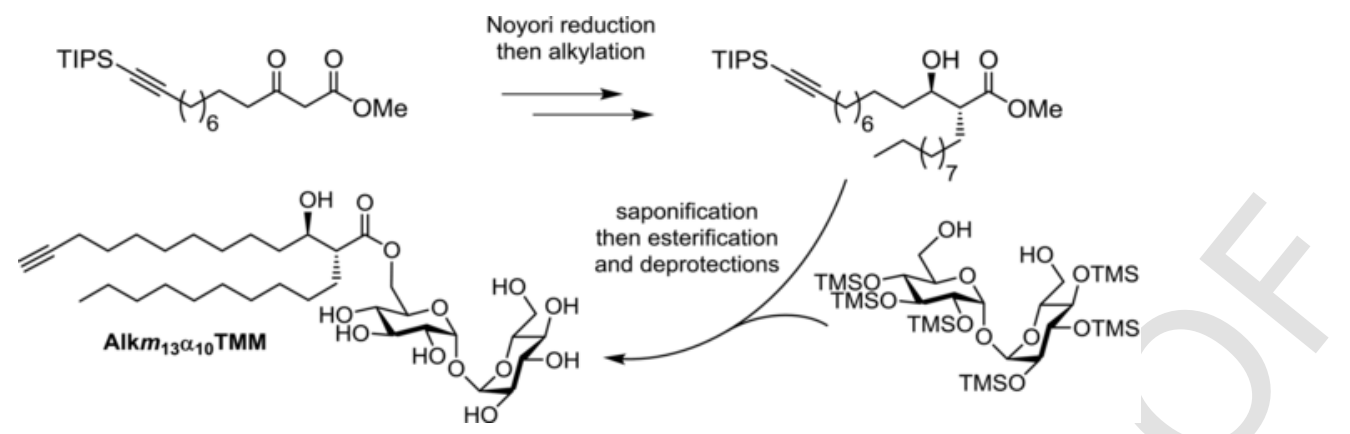

Scheme 14 Access to TMM-like probe including the characteristic pattern of mycolic acids.

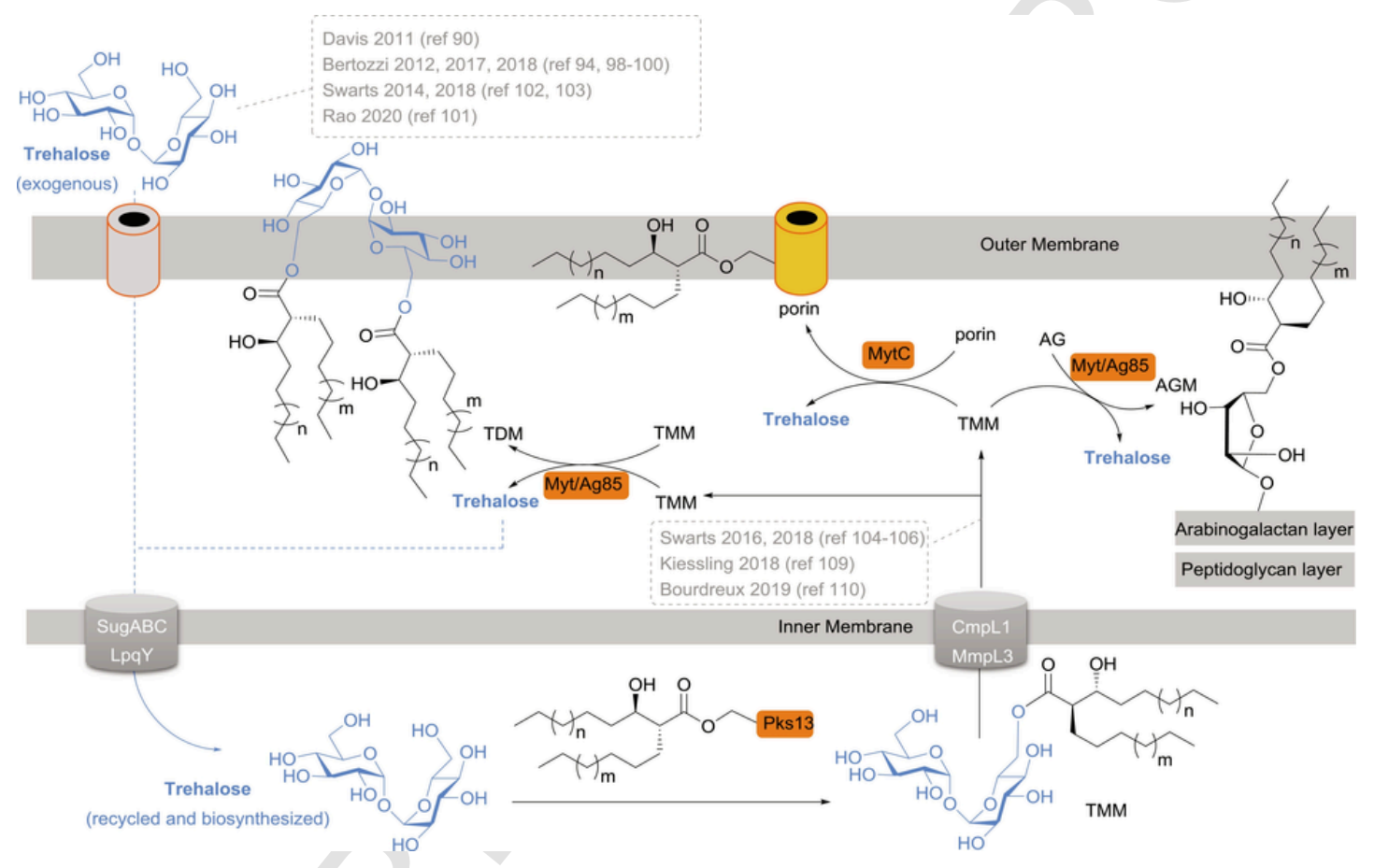

Fig. 13 Schematic overview of trehalose processing in mycobacteria.

proteins forming heterooligomeric complexes with channel-forming activity in the outer membrane. ${ }^{111,112}$ The transfer of mycolic acids on their various acceptors is catalyzed by multiple mycoloyltransferases that are key enzymes in the biogenesis of the envelope of Corynebacteriales. Four Ag85 have been described in M. tuberculosis, $6 \mathrm{Fbp}$ in M. smegmatis and 6 Myt in C. glutamicum which are the most studied Corynebacteriales so far. ${ }^{113}$ They are collectively involved in the transfer of mycoloyl groups on trehalose and on the arabinose of AG but their individual in vivo specificity remains elusive. ${ }^{114,115}$ Only MytC in C. glutamicum has been shown to be mainly involved in the mycoloyltransfer on proteins rather than on sugar acceptors. ${ }^{116}$ Once mycolic acid is transferred onto their acceptors, the released trehalose is recycled and goes back to the cytoplasm through a specific transporter.

Davis and Barry reported a library of trehalose analogs to explore the substrate tolerance of the Mtb mycoloyltransferases Ag85 and these compounds were screened using a mass spectrometry based assay in vitro. ${ }^{90}$ Interestingly, this study revealed a strong Ag85 plasticity for several trehalose analogs including a $\mathrm{C} 1$ methyl group at the anomeric position and even with a bulky FITC at position C2 linked by a thiourea. This trehalose-based fluorescent probe was used in metabolic labeling experiments on growing $M t b$ producing fluorescent bacteria with an accumulation of probe at the bacterial poles and membrane. FITC-trehalose (FITC-Tre) was also used to specifically label Mtb within infected macrophages opening up perspectives for use as a diagnostic tool as discussed below. Shortly after this first study, Bertozzi et al. reported a collection of azide-modified trehaloses (TreAz) at each position (C2, C3, C4, C6) allowing a two-step labeling approach through the bioorthogonal chemical reporter strategy using alkyne-functionalized fluorescent probes. ${ }^{94}$ These compounds, when combined with mutants missing the trehalose transporter, proved to be efficient tools to study the trehalose metabolism in live mycobacteria (Msmeg, $B C G, M t b)$ with perspectives for imaging glycolipids distribution in various conditions. 
Mycobacterial membrane protein Large 3 (MmpL3) is essential and required for transport of TMMs. In order to study the mechanism of action of piperidinol-containing molecules, 6-TreAz was fed to spheroplasts, incorporated into 6-azido-TMM in the cytoplasmic membrane and then labeled with alkyne-containing biotin. This study evidenced the mechanism of inhibition of this anti-tubercular drug that is mediated by the flippase activity of MmpL3 and TMM flipping was evidenced. ${ }^{117}$

In spite of the advantages of this labeling approach, Bertozzi returned to one-step labeling to study the mycobacterial membrane dynamics in several species (Mycobacterium, Corynebacterium, Nocardia and Rhodococcus) and described FITre analogs bearing the FITC at each trehalose position and differing from the previously reported FITC-Tre by lacking the anomeric methyl group. These probes have proven to be more efficient in labeling M. smegmatis and C. glutamicum than the slightly modified trehalose FITC-Tre. Fluorescence recovery after photobleaching (FRAP) experiments were applied to elucidate the mobility of labeled glycolipids in mycobacteria in several conditions including antibiotic treatment and providing insight into drugs effects in cell envelope biogenesis in live $M t b .{ }^{98}$ A tetramethylrhodamine-trehalose (TMR-Tre) conjugate was also successfully used by the same team to visualize the mycomembrane with super-resolution microscopy and to probe the relationship between mycomembrane and peptidoglycan dynamics using a dual metabolic labeling strategy. ${ }^{99}$ Since high background signal is one of the main drawback of FITC trehalose derivatives, trehalose conjugated to solvatochromic dye (4-N,N-dimethylamino-1,8-naphthalimide, DMN) were next introduced by Bertozzi as a new generation of trehalose-based fluorescent probes. DMN-Tre is sensitive to changes in the polarity of the medium and after its metabolic conversion into glycolipids and its incorporation into the mycomembrane, the probe undergoes a greater than 700 -fold increase in fluorescence intensity in hydrophobic environment. This probe does not require sample washing and has shown a strong potential to detect $M t b$ in patients' sputum, opening up interesting perspectives in the rapid diagnosis of Tuberculosis. ${ }^{100}$ Finally, a cephalosporinase-dependent green trehalose (CDG-Tre) fluorogenic probes was also reported by Rao. ${ }^{101}$ CDG-Tre is sequentially activated by two specific enzymes expressed in $M t b$ : the $\beta$-lactamase BlaC, release the caged fluorophore conjugated to trehalose resulting in fluorescence turn-on and the mycoloyltransferase Ag85 allowing the trehalose processing and mycomembrane labeling. CDG-Tre provides a new efficient approach using low concentration for the labeling of phagocytosed live BCG within macrophages.

TMM-based reporters have also been developed by Swarts for detecting MM components in mycobacteria. In these TMM mimics, the native mycolate is replaced by a shortened ester-linked acyl chain with a terminal chemical reporter group (i.e., alkyne, azide, trans-cyclooctene or fluorescent tags). ${ }^{104-106}$ Interestingly, $O$-AlkTMM, containing an alkyne-tagged short alkyl chain (C5-11) in place of the mycolic acid are processed in Mycobacteria by mycoloyltransferases allowing the transfer of an alkyne onto their acceptor substrates i.e., AG residue and TMM and then enabling selective in situ detection of the mycomembrane components TDM and mycolyl-arabinogalactan-peptidoglycan in Mycobacteria. These probes have potential for detection of mycobacteria in several environmental conditions or during infections. In the specific case of Corynebacterium glutamicum, which possesses a mycoloyltransferase $(\mathrm{MytC})$ capable of $O$-mycoloylating pore-forming proteins on a serine residue, $O$-Alk-TMM was used to label and identify other proteins that could be putatively mycoloylated. ${ }^{105}$ Such probes should help to characterize the whole $O$-mycoloylome in several Corynebacteria strains including human pathogens.

These probes have proven to be valuable tools for the study of mycomembrane but the process by which the lipid chain surrogate is transferred onto the acceptor in cell is somewhat unclear. Mycoloyltransferases proceed through two transesterification steps involving the serine of a catalytic triad. ${ }^{113}$ Several previous structural studies afforded mechanistic models underlying the role of the mycolate $\alpha$-chain in the binding of TMM and the crucial conformational changes involved to block the hydrolysis of the acyl-enzyme intermediate. ${ }^{118-120}$ When interacting with unbranched lipid, a substantial acylhydrolase activity was already reported with Ag85s. ${ }^{121}$ In that respect, Kiessling group developed an ingenious quencher-trehalose-fluorophore probe QTF with an unbranched lipid bearing the fluorophore moiety to promote hydrolysis of the acyl-enzyme intermediate enabling real-time imaging in native cellular environment. ${ }^{109}$ If such activity occurs in the labeling experiments with the short non-branched acyl TMM-based reporters, probes including the characteristic pattern of mycolic acids should make it possible to avoid this hydrolysis reaction and improve the native transfer activity of mycolate to its acceptors. To this end, Bourdreux and Guianvarc'h developed alkyne-based TMM probes including either a simple $\beta$-hydroxylated fatty acid chain which is a hallmark of the natural meromycolate chain Alk $m_{13} \alpha_{0} \mathrm{TMM}$ or an extra $\alpha$-branched chain similar to those of mycolic acids and most closely mimicking TMM, Alkm $m_{13} \alpha_{10}$ TMM. ${ }^{110}$ This latter demonstrated its utility to label mycomembrane with a short labeling time and very low doses in C. glutamicum and to study mycoloyltransferases in vitro since the mycolic acid analogs based-probe most closely mimicking TMM, Alk $m_{13} \alpha_{10} \mathrm{TMM}$, showed different behavior in comparison with the unbranched lipid-trehalose probe.

\section{Conclusion and outlook}

This book chapter focused on some issues and strategies concerning metabolic labeling of bacterial glycans. Due to the rapidly increasing development of in vivo chemistry, the use of bioorthogonal chemical reporters became inevitable. Thus, the examples reported here highlight the benefit of existing metabolic reporters for bacterial glycans. Labeling of other types of bio(macro)molecules (proteins, nucleic acids...) is still challenging. For further extensions of the strategies described in this work, investigations on multimodal labeling, single cells studies and/or multiple labeling techniques involving mutually orthogonal, bioorthogonal reactions are required. Dynamics, and real time imaging of metabolism might represent future developments, as well as the discovery of new, still unidentified or uncharacterized bacterial metabolic pathways. Some issues still remain unresolved, such as the exploration of the microbiota (culturomics). Labeling of bacteria within a live infected host, or within infected or phagocytic cells represent challenges that, up until now have been addressed by very few studies and more work could lead to better understanding of infection mechanisms. These labeling tools will also find applications in the development of new antibacterial agents, disease diagnosis, the characterization of new therapeutic targets, and the study of poorly understood but potentially curable diseases.

We hope that this book chapter will stimulate the imagination of the reader. 


\section{Acknowledgments}

C.B. and B.V. acknowledge the support of the French Agence Nationale de la Recherche (ANR) under reference NEURAPROBE ANR-18-CE07-0042. C.B. thanks Elisabeth Elass for stimulating helpful discussion. BV would like to thank Dr. Mathieu Carlier for his helpful input.

\section{References}

1.. $\quad$ R.Y. Tsien, The Green Fluorescent Protein, Annu. Rev. Biochem. 67 (1) (1998) 509-544.

2.. $\quad$ B.N.G. Giepmans, S.R. Adams, M.H. Ellisman, R.Y. Tsien, The Fluorescent Toolbox for Assessing Protein Location and Function, Science 312 (5771) (2006) 217-224.

3.. U. Weill, G. Krieger, Z. Avihou, R. Milo, M. Schuldiner, D. Davidi, Assessment of GFP Tag Position on Protein Localization and Growth Fitness in Yeast, J. Mol. Biol. 431 (3) (2019) 636-641.

4.. $\quad$ B.A. Griffin, S.R. Adams, R.Y. Tsien, Specific Covalent Labeling of Recombinant Protein Molecules inside Live Cells, Science 281 (5374) (1998) 269-272.

5.. H.J. Grünholz, E. Harms, M. Opetz, W. Reutter, M. Cerný, Inhibition of In Vitro Biosynthesis of N-Acetylneuraminic Acid by N-Acyl- and N-Alkyl-2-Amino-2-Deoxyhexoses, Carbohydr. Res. 96 (2) (1981) 259-270.

6.. D. Rideout, Self-Assembling Cytotoxins, Science 233 (4763) (1986) 561-563.

7.. $\quad$ L.K. Mahal, K.J. Yarema, C.R. Bertozzi, Engineering Chemical Reactivity on Cell Surfaces through Oligosaccharide Biosynthesis, Science 276 (5315) (1997) 1125-1128.

8.. K.J. Yarema, L.K. Mahal, R.E. Bruehl, E.C. Rodriguez, C.R. Bertozzi, Metabolic Delivery of Ketone Groups to Sialic Acid Residues. Application to Cell Surface Glycoform Engineering, J. Biol. Chem. 273 (47) (1998) 31168-31179.

9.. H.C. Hang, C. Yu, D.L. Kato, C.R. Bertozzi, A Metabolic Labeling Approach toward Proteomic Analysis of Mucin-Type O-Linked Glycosylation, Proc. Natl. Acad. Sci. 100 (25) (2003) 14846-14851.

10.. J.A. Prescher, C.R. Bertozzi, Chemistry in Living Systems, Nat. Chem. Biol. 1 (1) (2005) 13-21.

11.. H.C. Kolb, M.G. Finn, K.B. Sharpless, Click Chemistry: Diverse Chemical Function from a Few Good Reactions, Angew. Chem. Int. Ed. 40 (11) (2001) 2004-2021.

12.. H. Staudinger, J. Meyer, Über Neue Organische Phosphorverbindungen III. Phosphinmethylenderivate Und Phosphinimine, Helv. Chim. Acta 2 (1) (1919) 635-646.

13.. E. Saxon, C.R. Bertozzi, Cell Surface Engineering by a Modified Staudinger Reaction, Science 287 (5460) (2000) $2007-2010$.

14.. E. Saxon, S.J. Luchansky, H.C. Hang, C. Yu, S.C. Lee, C.R. Bertozzi, Investigating Cellular Metabolism of Synthetic Azidosugars with the Staudinger Ligation, J. Am. Chem. Soc. 124 (50) (2002) 14893-14902.

15.. R. Huisgen, 1,3-Dipolar Cycloadditions. Past and Future, Angew. Chem. Int. Ed. Engl. 2 (10) (1963) $565-598$.

16.. A. Michael, Ueber Die Einwirkung von Diazobenzolimid Auf Acetylendicarbonsäuremethylester, J. Für Prakt. Chem. 48 (1) (1893) 94-95.

17.. C.W. Tornøe, C. Christensen, M. Meldal, Peptidotriazoles on Solid Phase: [1,2,3]-Triazoles by Regiospecific Copper(I)-Catalyzed 1,3-Dipolar Cycloadditions of Terminal Alkynes to Azides, J. Org. Chem. 67 (9) (2002) 3057-3064.

18.. V.V. Rostovtsev, L.G. Green, V.V. Fokin, K.B. Sharpless, A Stepwise Huisgen Cycloaddition Process: Copper(I)-Catalyzed Regioselective "Ligation” of Azides and Terminal Alkynes, Angew. Chem. Int. Ed. 41 (14) (2002) 2596-2599.

19.. B.T. Worrell, J.A. Malik, V.V. Fokin, Direct Evidence of a Dinuclear Copper Intermediate in Cu(I)-Catalyzed Azide-Alkyne Cycloadditions, Science 340 (6131) (2013) 457-460.

20.. L. Jin, D.R. Tolentino, M. Melaimi, G. Bertrand, Isolation of Bis(Copper) Key Intermediates in Cu-Catalyzed Azide-Alkyne "Click Reaction.”, Sci. Adv. 1 (5) (2015), e1500304.

21.. M. Vrabel, T. Carell (Eds.), Cycloadditions in Bioorthogonal Chemistry, Topics in Current Chemistry Collections, Springer International Publishing, 2016.

22.. D.C. Kennedy, C.S. McKay, M.C.B. Legault, D.C. Danielson, J.A. Blake, A.F. Pegoraro, A. Stolow, Z. Mester, J.P. Pezacki, Cellular Consequences of Copper Complexes Used to Catalyze Bioorthogonal Click Reactions, J. Am. Chem. Soc. 133 (44) (2011) 17993-18001.

23.. Q. Wang, T.R. Chan, R. Hilgraf, V.V. Fokin, K.B. Sharpless, M.G. Finn, Bioconjugation by Copper(I)-Catalyzed Azide-Alkyne [3 + 2] Cycloaddition, J. Am. Chem. Soc. 125 (11) (2003) 3192-3193.

24.. C. Besanceney-Webler, H. Jiang, T. Zheng, L. Feng, D. Soriano del Amo, W. Wang, L.M. Klivansky, F.L. Marlow, Y. Liu, P. Wu, Increasing the Efficacy of Bioorthogonal Click Reactions for Bioconjugation: A Comparative Study, Angew. Chem. Int. Ed. Engl. 50 (35) (2011) $8051-8056$.

25.. A.T. Blomquist, L.H. Liu, Many-Membered Carbon Rings. VII. Cycloöctyne, J. Am. Chem. Soc. 75 (9) (1953) $2153-2154$.

26.. N.J. Agard, J.A. Prescher, C.R. Bertozzi, A Strain-Promoted [3 + 2] Azide - Alkyne Cycloaddition for Covalent Modification of Biomolecules in Living Systems, J. Am. Chem. Soc. 126 (46) (2004) 15046-15047.

27.. N.J. Agard, J.M. Baskin, J.A. Prescher, A. Lo, C.R. Bertozzi, A Comparative Study of Bioorthogonal Reactions with Azides, ACS Chem. Biol. 1 (10) (2006) 644-648.

28.. J.M. Baskin, J.A. Prescher, S.T. Laughlin, N.J. Agard, P.V. Chang, I.A. Miller, A. Lo, J.A. Codelli, C.R. Bertozzi, Copper-Free Click Chemistry for Dynamic In Vivo Imaging, Proc. Natl. Acad. Sci. U. S. A. 104 (43) (2007) 16793-16797.

29.. J.A. Codelli, J.M. Baskin, N.J. Agard, C.R. Bertozzi, Second-Generation Difluorinated Cyclooctynes for Copper-Free Click Chemistry, J. Am. Chem. Soc. 130 (34) (2008) 11486-11493.

30.. S.T. Laughlin, J.M. Baskin, S.L. Amacher, C.R. Bertozzi, In Vivo Imaging of Membrane-Associated Glycans in Developing Zebrafish, Science 320 (5876) (2008) 664-667.

31.. E.M. Sletten, C.R. Bertozzi, A Hydrophilic Azacyclooctyne for Cu-Free Click Chemistry, Org. Lett. 10 (14) (2008) 3097-3099.

32.. X. Ning, J. Guo, M.A. Wolfert, G.-J. Boons, Visualizing Metabolically Labeled Glycoconjugates of Living Cells by Copper-Free and Fast Huisgen Cycloadditions, Angew. Chem. Int. Ed Engl. 47 (12) (2008) 2253-2255.

33.. A. Kuzmin, A. Poloukhtine, M.A. Wolfert, V.V. Popik, Surface Functionalization Using Catalyst-Free Azide - Alkyne Cycloaddition, Bioconjug. Chem. 21 (11) (2010) 2076-2085. 
34.. M.F. Debets, S.S. van Berkel, S. Schoffelen, F.P.J.T. Rutjes, J.C.M. van Hest, F.L. van Delft, Aza-Dibenzocyclooctynes for Fast and Efficient Enzyme PEGylation Via Copper-Free (3 + 2) Cycloaddition, Chem. Commun. 46 (1) (2010) 97-99.

35.. J.C. Jewett, E.M. Sletten, C.R. Bertozzi, Rapid Cu-Free Click Chemistry with Readily Synthesized Biarylazacyclooctynones, J. Am. Chem. Soc. 132 (11) (2010) 3688-3690.

36.. E.M. Sletten, H. Nakamura, J.C. Jewett, C.R. Bertozzi, Difluorobenzocyclooctyne: Synthesis, Reactivity, and Stabilization by $\beta$-Cyclodextrin, J. Am. Chem. Soc. 132 (33) (2010) 11799-11805.

37.. R. van Geel, G.J.M. Pruijn, F.L. van Delft, W.C. Boelens, Preventing Thiol-Yne Addition Improves the Specificity of Strain-Promoted Azide-Alkyne Cycloaddition, Bioconjug. Chem. 23 (3) (2012) 392-398.

38.. K.E. Beatty, J. Szychowski, J.D. Fisk, D.A. Tirrell, A Bodipy-Cyclooctyne for Protein Imaging in Live Cells, Chembiochem 12 (14) (2011) 2137-2139.

39.. A.B. Neef, C. Schultz, Selective Fluorescence Labeling of Lipids in Living Cells, Angew. Chem. Int. Ed. 48 (8) (2009) 1498-1500.

40.. A.B. Neef, N.W. Luedtke, An Azide-Modified Nucleoside for Metabolic Labeling of DNA, ChemBioChem 15 (6) (2014) $789-793$.

41.. M.L. Blackman, M. Royzen, J.M. Fox, Tetrazine Ligation: Fast Bioconjugation Based on Inverse-Electron-Demand Diels-Alder Reactivity, J. Am. Chem. Soc. 130 (41) (2008) 13518-13519.

42.. E. Kuru, H.V. Hughes, P.J. Brown, E. Hall, S. Tekkam, F. Cava, M.A. de Pedro, Y.V. Brun, M.S. VanNieuwenhze, In Situ Probing of Newly Synthesized Peptidoglycan in Live Bacteria with Fluorescent D-Amino Acids, Angew. Chem. Int. Ed. 51 (50) (2012) 12519-12523.

43.. E. Kuru, A. Radkov, X. Meng, A. Egan, L. Alvarez, A. Dowson, G. Booher, E. Breukink, D.I. Roper, F. Cava, W. Vollmer, Y. Brun, M.S. VanNieuwenhze, Mechanisms of Incorporation for D-Amino Acid Probes That Target Peptidoglycan Biosynthesis, ACS Chem. Biol. 14 (12) (2019) 2745-2756.

44.. A.M. Di Guilmi, J. Bonnet, S. Peißert, C. Durmort, B. Gallet, T. Vernet, N. Gisch, Y.-S. Wong, Specific and Spatial Labeling of Choline-Containing Teichoic Acids in Streptococcus Pneumoniae by Click Chemistry, Chem. Commun. Camb. Engl. 53 (76) (2017) 10572-10575.

45.. J. Bonnet, Y.-S. Wong, T. Vernet, A.M. Di Guilmi, A. Zapun, C. Durmort, One-Pot Two-Step Metabolic Labeling of Teichoic Acids and Direct Labeling of Peptidoglycan Reveals Tight Coordination of Both Polymers Inserted into Pneumococcus Cell Wall, ACS Chem. Biol. 13 (8) (2018) 2010-2015.

46.. W. Vollmer, D. Blanot, M.A. de Pedro, Peptidoglycan Structure and Architecture, FEMS Microbiol. Rev. 32 (2) (2008) $149-167$.

47.. C.R.H. Raetz, C. Whitfield, Lipopolysaccharide Endotoxins, Annu. Rev. Biochem. 71 (2002) 635-700.

48.. S. Brown, J.P. Santa Maria, S. Walker, Wall Teichoic Acids of Gram-Positive Bacteria, Annu. Rev. Microbiol. 67 (2013).

49.. C. Hoffmann, A. Leis, M. Niederweis, J.M. Plitzko, H. Engelhardt, Disclosure of the Mycobacterial Outer Membrane: Cryo-Electron Tomography and Vitreous Sections Reveal the Lipid Bilayer Structure, Proc. Natl. Acad. Sci. U. S. A. 105 (10) (2008) 3963-3967.

50.. B. Zuber, M. Chami, C. Houssin, J. Dubochet, G. Griffiths, M. Daffé, Direct Visualization of the Outer Membrane of Mycobacteria and Corynebacteria in their Native State, J. Bacteriol. 190 (16) (2008) 5672-5680.

51.. A. Ortalo-Magné, A. Lemassu, M.A. Lanéelle, F. Bardou, G. Silve, P. Gounon, G. Marchal, M. Daffé, Identification of the Surface-Exposed Lipids on the Cell Envelopes of Mycobacterium Tuberculosis and Other Mycobacterial Species, J. Bacteriol. 178 (2) (1996) $456-461$.

52.. S. Pitarque, G. Larrouy-Maumus, B. Payré, M. Jackson, G. Puzo, J. Nigou, The Immunomodulatory Lipoglycans, Lipoarabinomannan and Lipomannan, Are Exposed at the Mycobacterial Cell Surface, Tuberc. Edinb. Scotl. 88 (6) (2008) 560-565.

53.. D. Chatterjee, C.M. Bozic, M. McNeil, P.J. Brennan, Structural Features of the Arabinan Component of the Lipoarabinomannan of Mycobacterium tuberculosis, J. Biol. Chem. 266 (15) (1991) 9652-9660.

54.. P. Messner, Bacterial Glycoproteins, Glycoconj. J. 14 (1) (1997) 3-11.

55.. I. Benz, M.A. Schmidt, Never Say Never Again: Protein Glycosylation in Pathogenic Bacteria, Mol. Microbiol. 45 (2) (2002) $267-276$.

56.. B.C. VanderVen, J.D. Harder, D.C. Crick, J.T. Belisle, Export-Mediated Assembly of Mycobacterial Glycoproteins Parallels Eukaryotic Pathways, Science 309 (5736) (2005) 941-943.

57.. C.-F. Liu, L. Tonini, W. Malaga, M. Beau, A. Stella, D. Bouyssié, M.C. Jackson, J. Nigou, G. Puzo, C. Guilhot, O. Burlet-Schiltz, M. Rivière, Bacterial Protein-O-Mannosylating Enzyme Is Crucial for Virulence of Mycobacterium Tuberculosis, Proc. Natl. Acad. Sci. 110 (16) (2013) $6560-6565$.

58.. G. Deng, W. Zhang, N. Ji, Y. Zhai, X. Shi, X. Liu, S. Yang, Identification of Secreted O-Mannosylated Proteins from BCG and Characterization of Immunodominant Antigens BCG_0470 and BCG_0980, Front. Microbiol. 11 (2020) 407.

59.. W. Qin, K. Qin, X. Fan, L. Peng, W. Hong, Y. Zhu, P. Lv, Y. Du, R. Huang, M. Han, B. Cheng, Y. Liu, W. Zhou, C. Wang, X. Chen, Artificial Cysteine S-Glycosylation Induced by Per-O-Acetylated Unnatural Monosaccharides during Metabolic Glycan Labeling, Angew. Chem. Int. Ed. 57 (7) (2018) $1817-1820$.

60.. A.K. Antonczak, Z. Simova, E.M. Tippmann, A Critical Examination of Escherichia coli Esterase Activity, J. Biol. Chem. 284 (42) (2009) 28795-28800.

61.. J. Mas Pons, A. Dumont, G. Sautejeau, E. Fugier, A. Baron, S. Dukan, B. Vauzeilles, Identification of Living Legionella Pneumophila Using Species-Specific Metabolic Lipopolysaccharide Labeling, Angew. Chem. Int. Ed Engl. 53 (5) (2014) 1275-1278.

62.. I. Nilsson, R. Prathapam, K. Grove, G. Lapointe, D.A. Six, The Sialic Acid Transporter NanT Is Necessary and Sufficient for Uptake of 3-Deoxy-D-Manno-Oct-2-Ulosonic Acid (Kdo) and Its Azido Analog in Escherichia Coli, Mol. Microbiol. 110 (2) (2018) 204-218.

63.. R. Sadamoto, K. Niikura, P.S. Sears, H. Liu, C.-H. Wong, A. Suksomcheep, F. Tomita, K. Monde, S.-I. Nishimura, Cell-Wall Engineering of Living Bacteria, J. Am. Chem. Soc. 124 (31) (2002) 9018-9019.

64.. H. Barreteau, A. Kovač, A. Boniface, M. Sova, S. Gobec, D. Blanot, Cytoplasmic Steps of Peptidoglycan Biosynthesis, FEMS Microbiol. Rev. 32 (2) (2008) 168-207.

65.. A. Bouhss, A.E. Trunkfield, T.D.H. Bugg, D. Mengin-Lecreulx, The Biosynthesis of Peptidoglycan Lipid-Linked Intermediates, FEMS Microbiol. Rev. 32 (2) (2008) 208-233.

66.. E. Sauvage, F. Kerff, M. Terrak, J.A. Ayala, P. Charlier, The Penicillin-Binding Proteins: Structure and Role in Peptidoglycan Biosynthesis, FEMS Microbiol. Rev. 32 (2) (2008) 234-258.

67.. R. Sadamoto, K. Niikura, T. Ueda, K. Monde, N. Fukuhara, S.-I. Nishimura, Control of Bacteria Adhesion by Cell-Wall Engineering, J. Am. Chem. Soc. 126 (12) (2004) 3755-3761.

68.. R. Sadamoto, T. Matsubayashi, M. Shimizu, T. Ueda, S. Koshida, T. Koda, S.-I. Nishimura, Bacterial Surface Engineering Utilizing Glucosamine Phosphate Derivatives as Cell Wall Precursor Surrogates, Chem. - Eur. J. 14 (33) (2008) 10192-10195.

69.. H. Liang, K.E. DeMeester, C.-W. Hou, M.A. Parent, J.L. Caplan, C.L. Grimes, Metabolic Labelling of the Carbohydrate Core in Bacterial Peptidoglycan and Its Applications, Nat. Commun. 8 (1) (2017) 15015.

70.. K.E. DeMeester, H. Liang, M.R. Jensen, Z.S. Jones, E.A. D’Ambrosio, S.L. Scinto, J. Zhou, C.L. Grimes, Synthesis of Functionalized N-Acetyl Muramic Acids to Probe Bacterial Cell Wall Recycling and Biosynthesis, J. Am. Chem. Soc. 140 (30) (2018) 9458-9465. 
71.. Y. Araki, S. Oba, S. Araki, E. Ito, Enzymatic Deacetylation of N-Acetylglucosamine Residues in Cell Wall Peptidoglycan, J. Biochem. (Tokyo) 88 (2) (1980) 469-479.

72.. J.M. Hansen, S.A. Golchin, F.J. Veyrier, P. Domenech, I.G. Boneca, A.K. Azad, M.V.S. Rajaram, L.S. Schlesinger, M. Divangahi, M.B. Reed, M.A. Behr, N-Glycolylated Peptidoglycan Contributes to the Immunogenicity but Not Pathogenicity of Mycobacterium tuberculosis, J. Infect. Dis. 209 (7) (2014) $1045-1054$

73.. D.H. Dube, K. Champasa, B. Wang, Chemical Tools to Discover and Target Bacterial Glycoproteins, Chem. Commun. 47 (1) (2010) 87-101.

74.. V.N. Tra, D.H. Dube, Glycans in Pathogenic Bacteria - Potential for Targeted Covalent Therapeutics and Imaging Agents, Chem. Commun. 50 (36) (2014) 4659-4673.

75.. M.B. Koenigs, E.A. Richardson, D.H. Dube, Metabolic Profiling of Helicobacter pylori Glycosylation, Mol. Biosyst. 5 (9) (2009) $909-912$.

76. F. Liu, A.J. Aubry, I.C. Schoenhofen, S.M. Logan, M.E. Tanner, The Engineering of Bacteria Bearing Azido-Pseudaminic Acid-Modified Flagella, Chembiochem Eur. J. Chem. Biol. 10 (8) (2009) 1317-1320.

77.. M. Sawa, T.-L. Hsu, T. Itoh, M. Sugiyama, S.R. Hanson, P.K. Vogt, C.-H. Wong, Glycoproteomic Probes for Fluorescent Imaging of Fucosylated Glycans In Vivo, Proc. Natl. Acad. Sci. 103 (33) (2006) 12371-12376.

78.. C. Besanceney-Webler, H. Jiang, W. Wang, A.D. Baughn, P. Wu, Metabolic Labeling of Fucosylated Glycoproteins in Bacteroidales Species, Bioorg. Med. Chem. Lett. 21 (17) (2011) 4989-4992.

79.. E.L. Clark, M. Emmadi, K.L. Krupp, A.R. Podilapu, J.D. Helble, S.S. Kulkarni, D.H. Dube, Development of Rare Bacterial Monosaccharide Analogs for Metabolic Glycan Labeling in Pathogenic Bacteria, ACS Chem. Biol. 11 (12) (2016) 3365-3373.

80.. J.M. Pickard, A.V. Chervonsky, Intestinal Fucose as a Mediator of Host-Microbe Symbiosis, J. Immunol. 194 (12) (2015) 5588-5593.

81.. W. Yi, X. Liu, Y. Li, J. Li, C. Xia, G. Zhou, W. Zhang, W. Zhao, X. Chen, P.G. Wang, Remodeling Bacterial Polysaccharides by Metabolic Pathway Engineering, Proc. Natl. Acad. Sci. 106 (11) (2009) 4207-4212.

82.. A. Dumont, A. Malleron, M. Awwad, S. Dukan, B. Vauzeilles, Click-Mediated Labeling of Bacterial Membranes through Metabolic Modification of the Lipopolysaccharide Inner Core, Angew. Chem. Int. Ed Engl. 51 (13) (2012) 3143-3146.

83.. M.A. Ghalambor, E.C. Heath, The Chemical Synthesis of 2-Keto-3-Deoxy-Octonate and Its Cleavage by a Specific Aldolase, Biochem. Biophys. Res. Commun. 11 (4) (1963) 288-293.

84.. E. Fugier, A. Dumont, A. Malleron, E. Poquet, J. Mas Pons, A. Baron, B. Vauzeilles, S. Dukan, Rapid and Specific Enrichment of Culturable Gram Negative Bacteria Using Non-Lethal Copper-Free Click Chemistry Coupled with Magnetic Beads Separation, Plos One 10 (6) (2015), e0127700.

85.. G. Andolina, R. Wei, H. Liu, Q. Zhang, X. Yang, H. Cao, S. Chen, A. Yan, X.D. Li, X. Li, Metabolic Labeling of Pseudaminic Acid-Containing Glycans on Bacterial Surfaces, ACS Chem. Biol. 13 (10) (2018) 3030-3037.

86.. H. Liu, Y. Zhang, R. Wei, G. Andolina, X. Li, Total Synthesis of Pseudomonas Aeruginosa 1244 Pilin Glycan Via de Novo Synthesis of Pseudaminic Acid, J. Am. Chem. Soc. 139 (38) (2017) 13420-13428.

87.. M. Kamariza, P. Shieh, C.R. Bertozzi, Imaging Mycobacterial Trehalose Glycolipids, Methods Enzymol. 598 (2018) 355-369.

88.. K. Kolbe, L. Möckl, V. Sohst, J. Brandenburg, R. Engel, S. Malm, C. Bräuchle, O. Holst, T.K. Lindhorst, N. Reiling, Azido Pentoses: A New Tool to Efficiently Label Mycobacterium tuberculosis Clinical Isolates, Chembiochem Eur. J. Chem. Biol. 18 (13) (2017) 1172-1176.

89.. S. Jana, S.S. Kulkarni, Synthesis of Trehalose Glycolipids, Org. Biomol. Chem. 18 (11) (2020) 2013-2037.

90.. K.M. Backus, H.L. Boshoff, C.S. Barry, O. Boutureira, M.K. Patel, F. D’Hooge, S.S. Lee, L.E. Via, K. Tahlan, C.E. Barry, B.G. Davis, Uptake of Unnatural Trehalose Analogs as a Reporter for Mycobacterium tuberculosis, Nat. Chem. Biol. 7 (4) (2011) 228-235.

91.. B.I. Glänzer, R. Csuk, Reaction of Pyranoid and Furanoid Aldonolactones with Chloromethyltrimethylsilane-Derived Reagents, Carbohydr. Res. 220 (1991) 79-92.

92.. H. Saito, H. Yoshikawa, Y. Nishimura, S. Kondo, T. Takeuchi, H. Umezawa, Studies on Lignan Lactone Antitumor Agents. I. Synthesis of Aminoglycosidic Lignan Variants Related to Podophyllotoxin, Chem. Pharm. Bull. (Tokyo) 34 (9) (1986) 3733-3740.

93.. R. Namme, T. Mitsugi, H. Takahashi, S. Ikegami, Development of Ketoside-Type Analogues of Trehalose by Using $\alpha$-Stereoselective O-Glycosidation of Ketose, Eur. J. Org. Chem. 2007 (22) (2007) 3758-3764.

94.. B.M. Swarts, C.M. Holsclaw, J.C. Jewett, M. Alber, D.M. Fox, M.S. Siegrist, J.A. Leary, R. Kalscheuer, C.R. Bertozzi, Probing the Mycobacterial Trehalome with Bioorthogonal Chemistry, J. Am. Chem. Soc. 134 (39) (2012) 16123-16126.

95.. P.A. Wallace, D.E. Minnikin, Synthesis of 2,3-Di-O-Palmitoyl- $\alpha, \alpha$-Trehalose via a Novel Tri-Protected Trehalose Intermediate, J. Chem. Soc. Chem. Commun. (16) (1993) 1292-1293.

96.. S. Hanessian, P. Lavallee, Synthesis of 6-Amino-6-Deoxy-, Trehalose: A Positional Isomer of Trehalosamine, J. Antibiot. (Tokyo) 25 (11) (1972) 683-684.

97.. R.W. Bassily, R.I. El-Sokkary, B.A. Silwanis, A.S. Nematalla, M.A. Nashed, An Improved Synthesis of 4-Azido-4-Deoxy- and 4-Amino-4-Deoxy- $\alpha, \alpha$-Trehalose and their Epimers, Carbohydr. Res. 239 (1993) 197-207.

98.. F.P. Rodriguez-Rivera, X. Zhou, J.A. Theriot, C.R. Bertozzi, Visualization of Mycobacterial Membrane Dynamics in Live Cells, J. Am. Chem. Soc. 139 (9) (2017) 3488-3495.

99.. F.P. Rodriguez-Rivera, X. Zhou, J.A. Theriot, C.R. Bertozzi, Acute Modulation of Mycobacterial Cell Envelope Biogenesis by Front-Line Tuberculosis Drugs, Angew. Chem. Int. Ed. 57 (19) (2018) 5267-5272.

100..M. Kamariza, P. Shieh, C.S. Ealand, J.S. Peters, B. Chu, F.P. Rodriguez-Rivera, M.R.B. Sait, W.V. Treuren, N. Martinson, R. Kalscheuer, B.D. Kana, C.R. Bertozzi, Rapid Detection of Mycobacterium tuberculosis in Sputum with a Solvatochromic Trehalose Probe, Sci. Transl. Med. 10 (430) (2018).

101..T. Dai, J. Xie, Q. Zhu, M. Kamariza, K. Jiang, C.R. Bertozzi, J. Rao, A Fluorogenic Trehalose Probe for Tracking Phagocytosed Mycobacterium tuberculosis, J. Am. Chem. Soc. 142 (36) (2020) 15259-15264.

102..B.L. Urbanek, D.C. Wing, K.S. Haislop, C.J. Hamel, R. Kalscheuer, P.J. Woodruff, B.M. Swarts, Chemoenzymatic Synthesis of Trehalose Analogues: Rapid Access to Chemical Probes for Investigating Mycobacteria, ChemBioChem 15 (14) (2014) 2066-2070.

103..J.M. Groenevelt, L.M. Meints, A.I. Stothard, A.W. Poston, T.J. Fiolek, D.H. Finocchietti, V.M. Mulholand, P.J. Woodruff, B.M. Swarts, Chemoenzymatic Synthesis of Trehalosamine, an Aminoglycoside Antibiotic and Precursor to Mycobacterial Imaging Probes, J. Org. Chem. 83 (15) (2018) 8662-8667.

104..H.N. Foley, J.A. Stewart, H.W. Kavunja, S.R. Rundell, B.M. Swarts, Bioorthogonal Chemical Reporters for Selective In Situ Probing of Mycomembrane Components in Mycobacteria, Angew. Chem. Int. Ed Engl. 55 (6) (2016) 2053-2057.

105..H.W. Kavunja, B.F. Piligian, T.J. Fiolek, H.N. Foley, T.O. Nathan, B.M. Swarts, A Chemical Reporter Strategy for Detecting and Identifying O-Mycoloylated Proteins in Corynebacterium, Chem. Commun. Camb. Engl. 52 (95) (2016) 13795-13798.

106..T.J. Fiolek, N. Banahene, H.W. Kavunja, N.J. Holmes, A.K. Rylski, A.A. Pohane, M.S. Siegrist, B.M. Swarts, Engineering the Mycomembrane of Live Mycobacteria with an Expanded Set of Trehalose Monomycolate Analogues, Chembiochem Eur. J. Chem. Biol. 20 (10) (2019) 1282-1291. 
107..R. Toubiana, B.C. Das, J. Defaye, B. Mompon, M.-J. Toubiana, Étude Du Cord-Factor et de Ses Analogues.: Partie III. Synthèse Du Cord-Factor (6,6'-Di-O-Mycoloyl- $\alpha, \alpha$-Tréhalose) et Du 6,6'-Di-O-Palmitoyl- $\alpha, \alpha$-Tréhalose, Carbohydr. Res. 44 (2) (1975) $308-312$.

108..V.A. Sarpe, S.S. Kulkarni, Synthesis of Maradolipid, J. Org. Chem. 76 (16) (2011) 6866-6870.

109..H.L. Hodges, R.A. Brown, J.A. Crooks, D.B. Weibel, L.L. Kiessling, Imaging Mycobacterial Growth and Division with a Fluorogenic Probe, Proc. Natl. Acad. Sci. 115 (20) (2018) 5271-5276.

110..E. Lesur, A. Baron, C. Dietrich, M. Buchotte, G. Doisneau, D. Urban, J.-M. Beau, N. Bayan, B. Vauzeilles, D. Guianvarc'h, Y. Bourdreux, First Access to a Mycolic Acid-Based Bioorthogonal Reporter for the Study of the Mycomembrane and Mycoloyltransferases in Corynebacteria, Chem. Commun. Camb. Engl. 55 (87) (2019) 13074-13077.

111..C. Carel, J. Marcoux, V. Réat, J. Parra, G. Latgé, F. Laval, P. Demange, O. Burlet-Schiltz, A. Milon, M. Daffé, M.G. Tropis, M.A.M. Renault, Identification of Specific Posttranslational O-Mycoloylations Mediating Protein Targeting to the Mycomembrane, Proc. Natl. Acad. Sci. U. S. A. 114 (16) (2017) 4231-4236.

112..H. Issa, E. Huc-Claustre, T. Reddad, N. Bonadé Bottino, M. Tropis, C. Houssin, M. Daffé, N. Bayan, N. Dautin, Click-Chemistry Approach to Study Mycoloylated Proteins: Evidence for PorB and PorC Porins Mycoloylation in Corynebacterium Glutamicum, PloS One 12 (2) (2017), e0171955.

113..N. Dautin, C. de Sousa-d'Auria, F. Constantinesco-Becker, C. Labarre, J. Oberto, I.L. de la Sierra-Gallay, C. Dietrich, H. Issa, C. Houssin, N. Bayan, Mycoloyltransferases: A Large and Major Family of Enzymes Shaping the Cell Envelope of Corynebacteriales, Biochim. Biophys. Acta Gen. Subj. 1861 (1 Pt B) (2017) 3581-3592.

114..S. Brand, K. Niehaus, A. Pühler, J. Kalinowski, Identification and Functional Analysis of Six Mycolyltransferase Genes of Corynebacterium Glutamicum ATCC 13032: The Genes Cop1, Cmt1, and Cmt2 Can Replace Each Other in the Synthesis of Trehalose Dicorynomycolate, a Component of the Mycolic Acid Layer of the Cell Envelope, Arch. Microbiol. 180 (1) (2003) 33-44.

115..C. De Sousa-D’Auria, R. Kacem, V. Puech, M. Tropis, G. Leblon, C. Houssin, M. Daffé, New Insights into the Biogenesis of the Cell Envelope of Corynebacteria: Identification and Functional Characterization of Five New Mycoloyltransferase Genes in Corynebacterium Glutamicum, FEMS Microbiol. Lett. 224 (1) (2003) 35-44.

116..E. Huc, C. de Sousa-D'Auria, I.L. de la Sierra-Gallay, C. Salmeron, H. van Tilbeurgh, N. Bayan, C. Houssin, M. Daffé, M. Tropis, Identification of a Mycoloyl Transferase Selectively Involved in O-Acylation of Polypeptides in Corynebacteriales, J. Bacteriol. 195 (18) (2013) $4121-4128$.

117..C. Dupont, Y. Chen, Z. Xu, F. Roquet-Banères, M. Blaise, A.-K. Witt, F. Dubar, C. Biot, Y. Guérardel, F.P. Maurer, S.-S. Chng, L. Kremer, A Piperidinol-Containing Molecule Is Active against Mycobacterium Tuberculosis by Inhibiting the Mycolic Acid Flippase Activity of MmpL3, J. Biol. Chem. 294 (46) (2019) 17512-17523.

118..K.M. Backus, M.A. Dolan, C.S. Barry, M. Joe, P. McPhie, H.I.M. Boshoff, T.L. Lowary, B.G. Davis, C.E. Barry, The Three Mycobacterium tuberculosis Antigen 85 Isoforms Have Unique Substrates and Activities Determined by Non-Active Site Regions, J. Biol. Chem. 289 (36) (2014) $25041-25053$.

119..D.H. Anderson, G. Harth, M.A. Horwitz, D. Eisenberg, An Interfacial Mechanism and a Class of Inhibitors Inferred from Two Crystal Structures of the Mycobacterium tuberculosis 30 KDa Major Secretory Protein (Antigen 85B), a Mycolyl Transferase, J. Mol. Biol. 307 (2) (2001) 671-681.

120..D.R. Ronning, V. Vissa, G.S. Besra, J.T. Belisle, J.C. Sacchettini, Mycobacterium Tuberculosis Antigen 85A and 85C Structures Confirm Binding Orientation and Conserved Substrate Specificity, J. Biol. Chem. 279 (35) (2004) 36771-36777.

121..C.S. Barry, K.M. Backus, C.E. Barry, B.G. Davis, ESI-MS Assay of M. tuberculosis Cell Wall Antigen 85 Enzymes Permits Substrate Profiling and Design of a Mechanism-Based Inhibitor, J. Am. Chem. Soc. 133 (34) (2011) 13232-13235.

\section{Glossary}

Bioorthogonal chemical reporter strategy A chemical labeling strategy involving the incorporation into the cell of a chemical analog of the molecule of interest (chemical reporter) tagged with a bioorthogonal small functional group (chemical reporter group). This group/function is then linked to a detection probe in a second step using a bioorthogonal reaction, that is a specific reaction which is insensitive to conditions and functionalities present in a biological sample.

Metabolic labeling A strategy to label biomolecules by metabolic incorporation of a synthetic analog of a metabolic intermediate involved in the targeted pathway.

Bacterial cell envelope A complex, multilayered structure surrounding the bacterial cell, including membranes, peptidoglycans, and other polysaccharides and biomolecules.

BiographyYann Bourdreux received his PhD from the University of Versailles Saint-Quentin-en-Yvelines in 2005 in the field of asymmetric synthesis, under the supervision of Professor Christine Greck. After a postdoctoral position on total synthesis in the group of Dr. Charles Mioskowski at the Commissariat à l'énergie atomique, Saclay, he joined the group of Professor Jean-Marie Beau in 2007 at the University Paris-Sud and was appointed assistant professor in 2008 in the same group. His research interests are regioselective protection of carbohydrates, selective synthesis of bioactive compounds such as trehalose derivatives. He is now interested in chemical biology and works with Professor Dominique Guianvarc'h at Universite Paris-Saclay on the synthesis of chemical tools for the study of the cell wall of mycobacteria.

Dominique Guianvarc'h received a formation in biochemistry and chemistry from the University Pierre et Marie Curie in Paris. She received her PhD in Organic Chemistry in 2001 under the supervision of Professor Jean-Louis Fourrey at the Institut de Chimie des Substances Naturelles in Gif sur Yvette (France) on $C$-nucleosides and nucleic acids chemistry. She then pursued a post-doctoral training in the laboratory of Biophysics of Professor Claude Hélène at the Museum National d'Histoire Naturelle in Paris on the development of conjugated topoisomerase inhibitors. In 2003, she was appointed Associate Professor in the laboratory of Biomolecules founded by Professor Andrée Marquet at the University Pierre et Marie Curie. In 2007, she developed her own group devoted to the study of methyltransferases enzymes with chemical tools. In 2017, she was promoted Professor at the University Paris Saclay at the Institut de Chimie Moléculaire et des Matériaux d'Orsay (France). She is group leader of a team in bioorganic chemistry with complementary skills 
in carbohydrate and nucleic acid chemistry, protein engineering and enzymology. Her research interests are in the areas of chemical biology including the development of chemical probes to understand different biological issues involving enzymes with potential applications in the field of health.

Christophe Biot scientific background is characterized by a very strong thematic mobility reflecting his desire to explore the fields of chemistry, biochemistry and biophysics. He obtained his PhD in synthetic chemistry (1995-98) under the supervision of Pr. Jacques Brocard at the University of Lille. His collaboration with Dr. Daniel Dive at the Institut Pasteur de Lille allowed him to acquire solid knowledge at the interface between chemistry and biology. In order to extend his training in biochemistry, he then did a first post-doctoral fellowship $(2000-01)$ in the team of Dr. Elisabeth Davioud-Charvet at the Institute of Biology of Lille. Due to the need to characterize non-covalent interactions between ligand and protein at a molecular level, he did a second post-doctoral fellowship (2001-04) in bioinformatics at the Ecole Polytechnique in Bruxelles (Belgium) under the scientific direction of Pr. Marianne Rooman. He was then recruited at the University of Lille in 2004 as assistant professor in the Unit of Catalysis and Solid State Chemistry where he developed new areas of research, including the study of mechanisms of action of anti-infective agents. Wishing to develop his activities in the area of chemical biology in Lille, he approached the team of Dr. Yann Guérardel at the Unit of Structural and Functional Glycobiology in September 2009. After 1 year $(2010$ - 11) hosted by the CNRS, he then integrated the team. He was appointed Professor in 2012. Currently, Christophe Biot coordinates the Chemical GlycoBiology (CheGB) team with scientists displaying complementary know-how, from organic synthesis to cell biology. The research topics cover several aspects of high significance: from structural analysis of (glyco)macromolecules to medicinal chemistry.

Boris Vauzeilles is Former student of the Ecole Normale Supérieure in Paris, he prepared his PhD under the supervision of Prof. Pierre Sinaÿ in the Chemistry Department of this institution. He then joined Prof. Julius Rebek, Jr. at MIT (Cambridge, Massachussets), for a post-doctoral experience. The group soon moved to the Scripps Research Institute in La Jolla, where Julius Rebek was promoted as Director of the Skaggs Institute for Chemical Biology. Boris Vauzeilles then returned to France as a CNRS researcher (Institut de Chimie Moléculaire et des Matériaux d'Orsay, Université Paris-Saclay), and in 2012 he created, in parallel with his research in Orsay, a new team at the Institut de Chimie des Substances Naturelles in Gif-sur-Yvette, where he initiated in 2015 the Department of Chemical Biology. He is also the co-founder of a startup company, Diamidex, and was awarded, together with his group, the Prix La Recherche in 2015 . His research is mainly focused on the use of synthetic chemistry to develop molecular tools designed to probe biological processes. Mainly educated as a synthetic glycochemist, he evolved toward the development of eco-friendly chemistry starting from biomass, design and synthesis of molecular devices for artificial photosynthetic systems for energy conversion, in vivo chemistry with the metabolic labeling of living bacterial lipopolysaccharides, and the development of new molecular probes for reactive oxygen species. Since early 2020 , he is the Director of Institut de Chimie des Substances Naturelles. 